\title{
Effects of probiotic and alpha-lipoic acid supplements, separately or in combination on appetite in overweight individuals: A double blind randomized clinical trial
}

\author{
Gholamreza Nasiri ${ }^{1}$, Ali Bastani ${ }^{2}$, Ali Akbar Haji-Aghamohammadi ${ }^{3}$, Mohamadreza Rashidi
} Nooshabadi $^{4}$, Parviz Shahmirzalou ${ }^{5}$, Hossein Khadem Haghighian ${ }^{6,7}$

1. MSc, Student Research Committee, School of Health, Qazvin University of Medical Sciences, Qazvin, Iran. ORCID ID: 0000-0002-6015-1367

2. Assistant Professor, Department of Internal Medicine, Faculty of Medicine, Qazvin University of Medical Sciences, Qazvin, Iran. ORCID ID: 0000-0002- 5434-4939

3. Associate Professor, Department of Internal Medicine, Faculty of Medicine, Qazvin University of Medical Sciences, Qazvin, Iran. ORCID ID: 0000-0002- 9250-1037

4. Assistant Professor, Department of Pharmacology, School of Pharmacy, Ahvaz Jundishapur University of Medical Sciences, Ahvaz, Iran. ORCID ID: 0000-0002-1707-0094

5. Instructor, Department of Biostatistics, Khoy university of Medical Sciences, West Azerbaijan, Iran. ORCID ID: 00000002-1525-5191

6. Assistant Professor, Department of Nutrition, School of Health, Qazvin University of Medical Science, Qazvin, Iran. ORCID ID: 0000-0002- 7445-1846

7. Assistant Professor, Metabolic Diseases Research Center, Research Institute for Prevention of Non-Communicable Diseases, Qazvin University of Medical Sciences, Qazvin, Iran., (Corresponding author), Tel: 09148375283, E-mail: khademnut@yahoo.com, ORCID ID: 0000-0002-7445-1846

\section{ABSTRACT}

Background and Aim: The purpose of this study was to evaluate the effects of probiotic and alpha-lipoic acid (ALA) supplements, on appetite in overweight people.

Materials and Methods: This study included two phases of weight loss ( 8 weeks) and weight maintenance (16 weeks). Eighty-eight overweight people were randomly divided into 4 groups: Isocaloric diet with probiotic $(500 \mathrm{mg})$, isocaloric diet with ALA (600mg) and probiotic, isocaloric diet with ALA and isocaloric diet with placebo groups. In the second phase, the participants received normal diet with the above - mentioned supplements. At the beginning and end of the first phase and at the end of the second phase, weight, body mass index (BMI), waist circumference (WC), hip circumference (HC), body fat percentage, Creactive protein (CRP), and appetite were evalauted. We used SPSS software for statistical analysis. Independent sample t-test and ANOVA were used to compare the alterations in the mean values among the groups.

Results: At the end of the first phase, the level of anthropometric changes, inflammatory factor and appetite were significant in the intervention groups, but these changes were higher in the probiotic + ALA group than in the other groups $(\mathrm{P}<0.05)$. At the end of the second phase we found significant changes only in the probiotic + ALA group $(\mathrm{P}<0.05)$.

Conclusion: Addition of probiotic and ALA supplements to the normal diet can be effective in appetite and weight management and also maintainance of weight loss which may be due to decreased inflammation.

Keywords: Probiotic, Alpha lipoic acid, Appetite, Overweight

Received: Oct 4, 2019 Accepted: Jan 28, 2020

\footnotetext{
How to cite the article: Gholamreza Nasiri, Ali Bastani, Ali Akbar Haji-Aghamohammadi, Mohamadreza Rashidi Nooshabadi, Parviz Shahmirzalou, Hossein Khadem Haghighian. Effects of Probiotic and Alpha-Lipoic Acid Supplements, Separately or in Combination on Appetite in Overweight Individuals: A Double Blind Randomized Clinical Trial. SJKU.

Copyright (C) 2018 the Author (s). Published by Kurdistan University of Medical Sciences. This is an open access article distributed under the terms of the Creative Commons Attribution-Non Commercial License 4.0 (CCBYNC), where it is permissible to download, share, remix, transform, and buildup the work provided it is properly cited. The work cannot be used commercially without permission from the journal 


\section{بررسى تأثير مكمل يارى بروبيوتيك و آلفالييوئيك اسيد به صورت جداكانه و همزمان بر روى

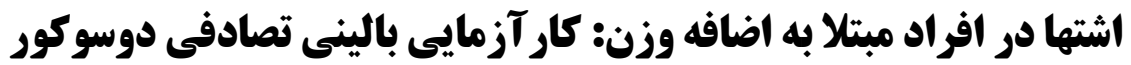

غلامرضا نصيرى'، على باستانى '، على اكبر حاجى آقا محمدى'؛ محمدرضا رشيدى نوش آبادى'، يرويز شاه ميرزالو؛، حسين خادم

حقيقيان

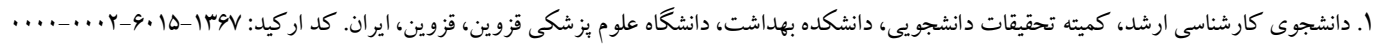

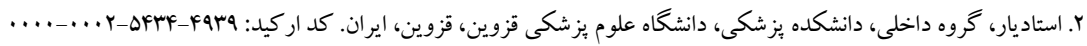

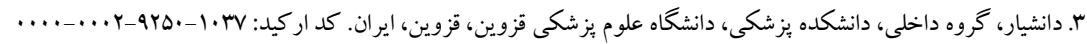

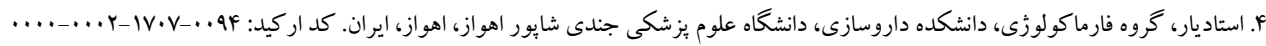

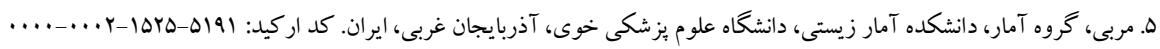

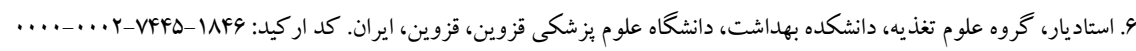

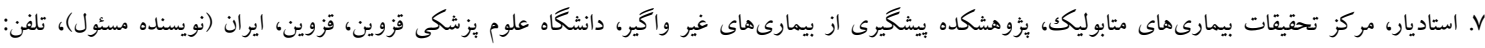

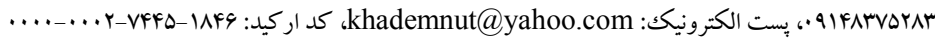

جكيده

زمينه و هدف: حفظ وزن كاهش يافته در اثر مداخلات تغذيهاى، براى برخوردارى از مزاياى سلامتى آن مهم است. اين مطالعه با هدف بررسى تأثير مكملهاى يروبيوتيكك و آلفا ليبوئيك اسيد (ALA) به طور جداكانه يا به صورت تركيبى بر ميزان اشتها در افراد داراى اضافه وزن انجام شد. مواد و روش ها: اين مطالعه كار آزمايى بالينى شامل دو فاز كاهش وزن (1 هفته) و حفظ وزن (19 هفته) بود. هشتاد و هشت فرد

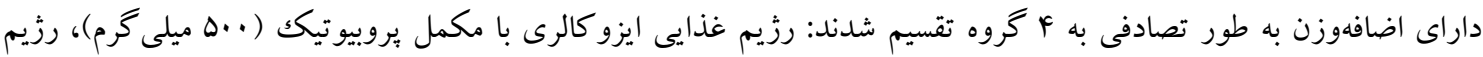
غذايى ايزو كالرى با بروبيوتيكك و ALA ( . .9 ميلى گرم)، رزيم غذايى ايزو كالرى با ALA و رزيم غذايى ايزو كالرى با دارونما. در فاز دوم، شركت كنند كان رزيم غذايى نرمال با مكملهاى ذكر شده دريافت كردند. در ابتدا و انتهاى فاز اول و در انتهاى فاز دوم، وزن، شاخص توده بدنى (BMI)، دور كمر (WC)، دور باسن (HC)، درصد جربى بلدن، يروتئين واكنش گر (CRP) C اشتها اندازهگيرى شد. تجزيهوتحليل آمارى با نرمافزار SPSS انجام و آزمون Independent sample t test و ANOVA جهت مقايسه ميانكين تغييرات بين دو گروه و خروهها استفاده گرديد. يافتهها: در انتهاى فاز اول، ميانكين دادههاى تنسنجى، فاكتور التهابى و اشتها در گروههاى مداخله به طور معنىدارى كاهش يافته بود ولى ميزان اين تغييرات در گرووه دريافت كننده يروبيوتيك و ALA نسبت به ساير گروهها بيشتر بود (ه •/• P). همجنين در

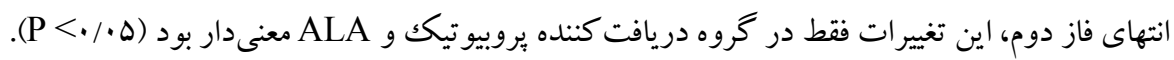
نتيجه تيرى: مكمل هاى يروبيو تيك و ALA به كاهش و حفظ وزن و اشتها به همراه رزيم نرمال كمكك مى كنند. علت اين امر ممكن است به دليل كاهش التهاب باشد. كلمات كليدى: يروبيو تيك، آلفا لييوئيك اسيد، اشتها، اضافه وزن

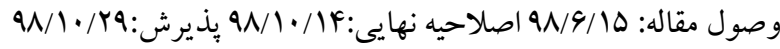


ا س كيلو گرم بر متر مربع گزارش شده است كه بدون هيج عارضه جانبى بوده است(^). يروبيوتيككها ميكروار گانيسم

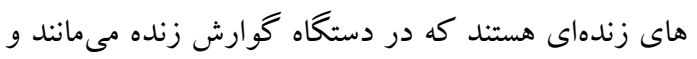
در صورتى كه به مقدار كافى مصرف شوند، مزيتهاى سودمند سلامت را در ميزبان ايجاد مى كنند. نشان دادهده است كه يروبيوتيككها در روده داراى عملكردهاى ضد سمى در برابر عوامل بيمارىزاى خاص، فعاليت ضد ميكروبى، حفظ اتصالات محكم، تنظيم فلور روده و فعاليت

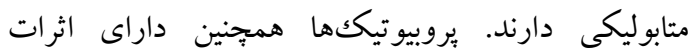
تغذيهاى و ضد التهابى براى مخاط هستند(9). اخيراً يكى فرضيه، ميكروبيو تاى روده را به عنوان ابزار كنترل وزن بدن بهن و متابوليسم انرزى معرفى مى كند كه در دو علت اصلى جاقى يعنى جذب انرزى و ذخيرهسازى تأثير دارد( •(). در اولين مطالعه انسانى كه از سويه Lactobacillus gasseri SBT2055 استفاده شد، كاهش معنىدار وزن، دور كمر، دور باسن و مساحت جربى شكمى را گزارش نمود(11). افزايش ميزان جاقى، حفظ ثبات داخلى (هموستاز) را با توليد بيش از حد اكسيدانها، فعالسازى و نفوذ ماكروفازها و ساير سلولهاى ايمنى بدن مختل مى كند، در نتيجه از اين دو راه باعث تحريكك فر آيندهاى التهابى در بافت جربى وسى و

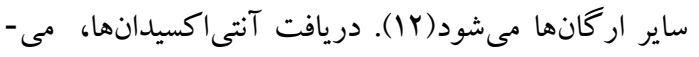
تو اند به كاهش و خنثى سازى اكسيدانها كمكك كننده باشد. آلفا لييوئيك اسيد، يكك اسيد جرب طبيعى كوتاه زنجير داراى گروه سولفيدريل است كه يكك آنتىاكسيدان قوى هست، و يكى از اجزاى مهم آنزيمهاى تنفسى ميتو كندرى

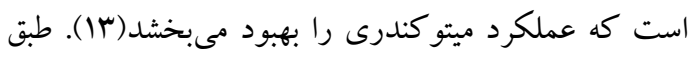

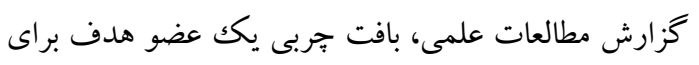
فعاليتهاى ضد جاقى اين آنتى اكسيدان معرفىشده است كه باعث تنظيم متابوليسم كلوكز و جربى در اين اركان مى -

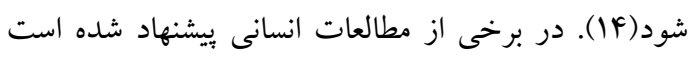

مقدمه

امروزه جاقى در تمام دنيا به عنوان يكك بيمارى فراكير

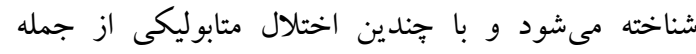

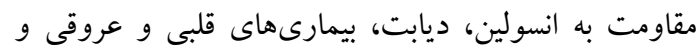

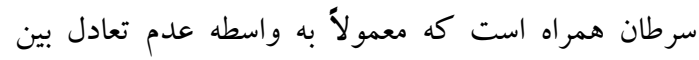

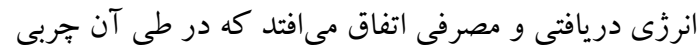
در بدن انباشته مىشود(1). طبق تعريف سازمان بهداشت

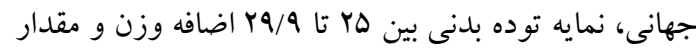

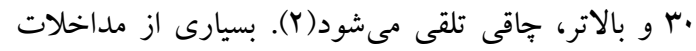
منجر به كاهش وزن مىشوند، با اين حال انجام اين مداخلات اغلب با افزايش اشتها همراه است كه در نتيجه كاهش وزن را با محدوديت مو اجه مى كند و در نتيجه حفظ وزن كاسته شده به يكك جالش واقعى تبديل مىشود (r). رزيم هاى غذايى كه معمولاً براى مقابله با جاقى استفاده

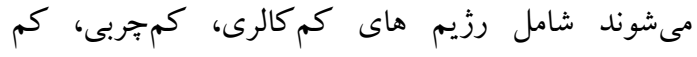

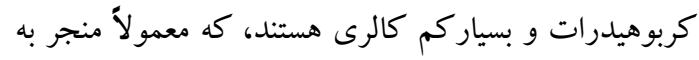

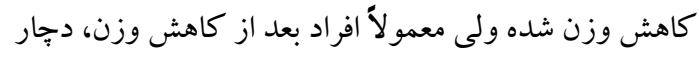
باز گشت وزن مىشوند. با اين حال حفظ وزن كاهش ولى يافته براى برخوردارى از مزاياى سودمند سلامتى آن بسيار مهم

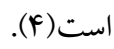
مكملهاى آنتى اكسيدانى اثرات متفاوتى در مديريت جاقى

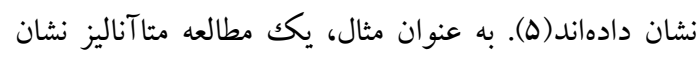
داد كه كاتجين (يلى فنول جاى سبز) نسبت به دارونما باعث

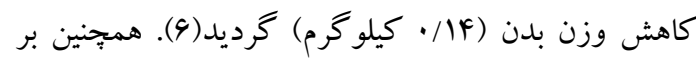
اساس يكك مطالعه كار آزمايى بالينى، مكمل روى باعث كاهش وزن بدن (1/V كيلو گرم) در كود كان خاق بدون عوارض جانبى بعد از ^ هفته گرديد(V). در يكك مطالعه مرورى مشخص گرديد كه مطالعات بالينى محدودى در مورد مكملهاى رزوراترول، كوئرستين و هسبريدين وجود دارد كه در آن ها اثرات ضد جاقى آن ها بررسى شده است.

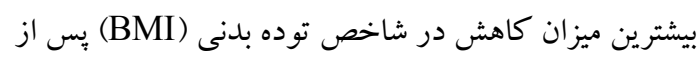
مصرف مكمل هاى ذكر شده در مورد رزوراترول به ميزان 
مى توانست مطالعه را تركى كند. در اين مطالعه براى مداخله. از دو نوع كِيسول مكمل و يكك نوع كيسول دارونما استفاده

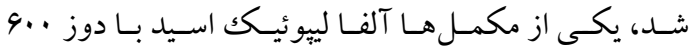
ميلى گرم روزانه بـود و ديخـرى كيسـول مكمـل بِروبيو تيكك بـود كـه توسـط شـر كت زيسـت تخميسر آمـاده شـده بـود.

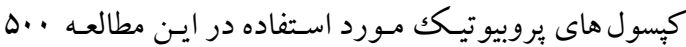
ميلى كرم وزن داشتند. تر كيب اين كِيسول ها عبارت بود از: Lactobacillus casei

Lactobacillus rhamnosus

\section{Lactobacillus bulgaricus}

\section{Lactobacillus acidophilus}

\section{Bifidobacterium breve}

Bifidobacterium longum

Streptococcus thermophilus

TVC: $2 * 1011 \mathrm{CFU}$

كيسـولهــاى دارونمـا نيـز بـه شـكل و رنـحك كيسـولهـاى

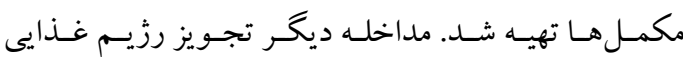
ايزو كالرى بود(19). در رزيم غذايى ايزو كالرى ميزان انرزى مصرفى روزانه هر فرد، مطابق با وزن ايده آل بدن و بر اساس نياز روزانه فرد است كه انرزى كمترى نسبت بـه رزيـم قبلى مصرف مى كند و اين باعث كاهش وزن با ادامه مصرف آن مسى شـود. شـر كت كنتـد گان هاه درصــ كربوهيـدرات، .ب درصد جربسى و ها درصـد يسروتئين دريافت كردنــ. ميزان Mifflin-St Jeor انرزى مورد نيـاز افراد بـر اسـاس معادلـه محاسبه گرديد. كد گذارى بستههاى حاوى مكمل ها، توسط فردى غيـر از بزوهشـران بـه صسورت الـف، ب، ج و د انجام گرفت و افراد داوطلب به صورت تصادفى در گروه هاى مداخله و دارونما قرار كرفتند. بيمـاران بـه ايسن صسورت كه به تعداد افـراد شـركت كنتـده كـارت هـايى بـا برجّــب الف، ب، ج و د (بـه صـورت مخلـوط) وجـود داشـت، بـا بيرون آوردن كارت ها بيماران به جهار گـروه تقسيم شـدند.
كه تر كيب بروبيو تيكك و آنتى اكسيدان مىتواند براى درمان كاهش وزن و حفظ وزن كاهش يافته كمك كننده باشد(ها). با اين حال، اطلاعات كمى در مورد اثرات مفيد مكمل هاى غذايى آلفا ليبيويكك اسيد و يروبيوتيكك بر روى اشتها و كاهش وزن در مطالعات انسانى مشاهده شده است. اين مطالعه با هدف تعيين تأثير مصرف يروبيوتيك و آلفا لييوئيك اسيد به صورت تركيبى و جداكانه در اشتهاى افراد داراى اضافه وزن انجام شد.

\section{مواد و روشها}

مطالعه حاضر از نوع كار آزمايى بالينى تصـادفى، دوسـو كور

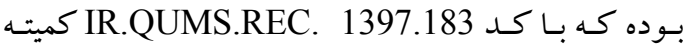

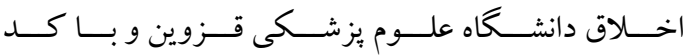
IRCT20141025019669N10 كار آزمايى بالينى ايران ثبت شد. جامعه مورد مطالعه ما افراد

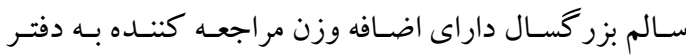
مشاوره تغذيه در بيمارسـتان ولايـت قـزوين بـود. تعـداد 4سا نفر داوطلب براى شركت در مطالعه ثبت نام كردند كه ياز غربالكرى تعداد M Mنفر در سنين \ا تـا •9 سـال وارد ايـن تحقيق شدند. همه شركت كنــــان قَّل از ورود بـه مطالعـهـ فرم رضايتنامه كتبى را تكميل كردند. معيارهـاى خـروج از مطالعه عبارت بودند از: باردارى يا زايمـان در سـال گذشـته، شيردهى، يائسكى، كاهش وزن بيش از لددرصـد در سـه مـاه قبل از ثبت نام در مطالعه يا هر كونـه اقـدام بـهـ جراحسى بـراى

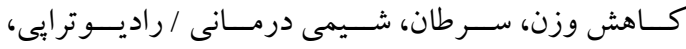
بيمارى هاى قلبى عروقى، كليه، كبد، تيروئيــ يـا غــد درون

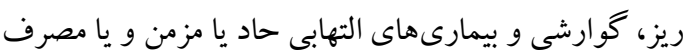

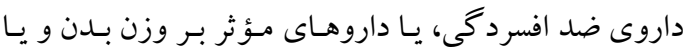
مصرف انرزى، يا مصرف دارو براى كنترل قند خون، جربسى خون و فشارخون، حساسيت غذايى و همبجنين عدم تمايل بـه ادامسه مطالعـه، در ضـمن اخَر فردى هـر زمـان مسىخواسـت 
متر محاسبه شد. همجنين درصد جِربى بدن در ابتداى مطالعه

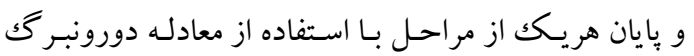
محاسبه شد(1) (1). مصرف غذايى و اطلاعات مربوط به غذاى دريافتى افراد با استفاده از ثبت YF ساعته غذايى (Y روز غير متوالى و ا روز تعطيل) در ابتداى مطالعـه از طريـق مصـاحبه جمع آورى شد. سبس كليه مواد غذايى مصرفى با اسـتفاده از مقادير و اوزان استاندارد ضرايب تبديل خام به بخته، به گـرم

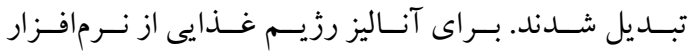
Nutritionist IV سهم مقدار درشت مغذىها (كربوهيدرات، يروتئين، جربسى) و همجنين مقدار فيبر غذايى محاسبه شد. همجنين در ابتـاى مطالعه، · ا سى سىى خـون بـه منظور انــازهذيـرى يـروتئين واكـش كر بيماران (CRP: C-reactive protein) C كر فته شد. همجِنين براى ارزيابى فعاليـت بـدنى از يرسشـنامه IPAQ: Internationa Physical ( بين المللى فعاليت بدنى IPAQ استفاده شد. دادههاى (Activity Questionnaire با استفاده از دستور العمل هاى موجود به معادل دقيقه در هفتـه تبـديل شـدند. بـراى انـدازه گيـرى اشـتها، شـركت كنتــــان مقياس آنالو گك ديـارى ..'اميلىمترى لمAS: Visual)

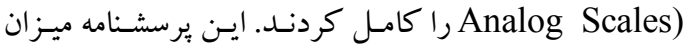
گرسـنَى، سـيرى، رضـايتمندى و توانـايى خـوردن را روى خط ارزيابى مى كند، نقطه ابتدايى خط (صفر ) به معنى اصـلاً و نقطه انتهايى خط (صد ) به معنى بسـيار زيـاد اسـت. بـراى ارزيابى ميزان اشتهاى فرد در هر روز از ميـانگين نمـرات هـر سؤال كه قبل از سه وعـده اصـلى غـذايى تكميـل شـــ مـورد استفاده قرار گرفت. روايى و هايايى برسشنامه قبلاً در مطالعـه اير انيارزيـابى شـده اسـت(9 19). بـراى تعيـين حجـم نمونـه، از فاكتور دور باسن (فاكتور مشابه بـا مطالعـه مـا) قبـل و بعــ از مداخلـه مربـوط بــه مطالعــه لــورنزو و همكــاران، اسـتفاده

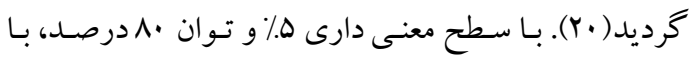

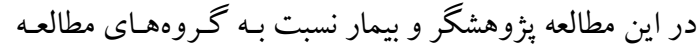
كور بودند. طول دوره مطالعـه حاضـر، 9 مـاه بـود كـه در دو مرحله دو ماهه و جهار ماهه بدون فاصله از هم اجـرا شـــ. در مرحله اول همه شركت كنــــان رزيـم غـذايى ايزوكـالرى همر اه با مصرف يكك يا دو كِيسول مكمـل يـا دارونمـا اجـرا كردند. در مرحله دوم شركت كنندگان رزيم غـذايى نرمـال را بدون مصرف مكمل يا دارونما اجرا كردند. قبل از شـروع

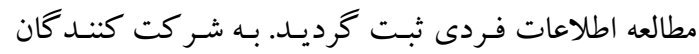
توصيه شد مكمل ها را به همر اه وعده غذايى مصـرف كننـد. دفترجه يادداشتى بـراى هـر فرد فـر اهم شـــه بـود تـا بتو انــــ وضعيت مصرف مكمل ها و يا يبندى به رزيـم غـذايى توصسيه شـده را در آن ثبـت كنتـد. در ايسن مرحلـه جلسـات مشـاوره حضورى هـر هفتـه يـك بـار بـه صـورت رايخـان بـراى همـه شر كت كنند گان مطالعه بر گزار گرديد و بررسى موارد ثبـت

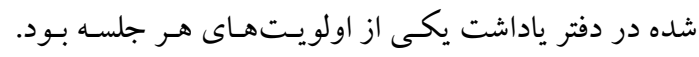
همجينين در مرحله اول مطالعه، هـر هفتـه يـككبـار وضعيت مصرف مكمل ها و يايبندى به رزيمهـاى غـذايى بـه صورت تلفنى بيخيـرى و در برونــدهـا ثبـت مسى شـد. شـاخصهـاى آنترويومتريكك شامل قد، وزن، دور كمر و دور باسن در اول

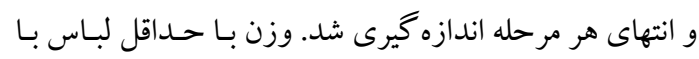

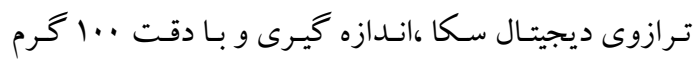
اندازه گيرى شد. قد به وسيله متر نوارى الصاق شده به ديـوار و با استفاده از يكك كونيا به صـورتى كـه يشـت سـر، كتـف،

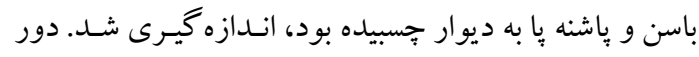
كمر با استفاده از يكك متـر نـوارى در كوجـك تـرين محسيط ناحيه مابين قفسه سينه و نـاف يـا نصـف ارتفـاع مـا بـين تـاج ايلياكك لكن تـا آخـرين دنـده در سـمت جـبِ انـدازه گيـرى

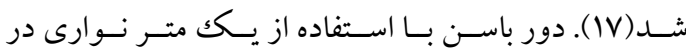
بزر گكترين قسمت محيط باسـن انسدازه گيـرى شـد. شـاخص توده بدنى از تقسيم وزن بدن به كيلو گرم بـر مجـذور قـد بـه 
استفاده گرديد. در اين :ثزوهش مقدار P-value كمتر از ه• • از نظر آمارى معنىدار در نظر گرفته شد.

كافتها

در اين مطالعه تعداد وسا فرد داراى اضافه وزن براى شركت در تحقيق ثبتنام كردند كه يس از غربالكرى، بر اساس معيارهاى ورود، تعداد N نفر واجد شرايط به طور تصادفى و با كور سازى دو طرفه در يكى از جهار گروه تحقيق تخصيص داده شدند. در طول مطالعه جهار نفر از شركت كنند گان به دلايل شخصى نتوانستند مطالعه را ادامه دهند و از مطالعه خارج شدند. سرانجام NF نفر توانستند هر دو مرحله مطالعه را به طور كامل انجام دادند. ميزان همكارى شر كت كنند گان در اين مطالعه ه\$/ه9 درصد بود. نمودار جريان انتخاب شر كت كنند كان در شكل ا نشان داده شده است.

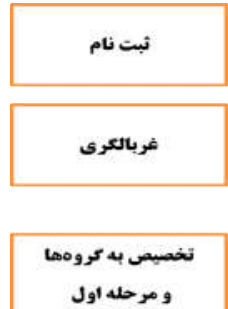

و مرحله اول

مرحله دوم
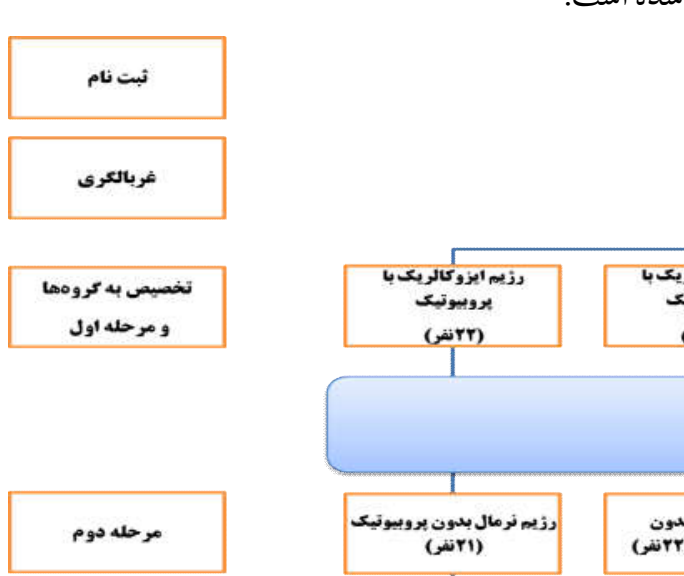

I

استفاده از فرمول زير، 19 نفر براى هر گرووه محاسبه گرديــد كه با احتساب ريزش، براى هر گروه بr نفـر در نظـر گر فتـه

$\mathrm{N}=\left[\left(\mathrm{Z}_{1-\alpha / 2}+\mathrm{Z}_{1-\beta}\right)^{2}\left(\mathrm{SD}_{1}{ }^{2}+\mathrm{SD}_{2}{ }^{2}\right)\right] / \Delta^{2}$

براى تجزيه و تحليل آمارى يافتهها از نرم افزار SPSS نسخه ·r Statistics كمى از ميانگين و انحراف معيار استفاده گرديد. براى اطمينان از نرمال بودن توزيع يافته از آزمون one-sample Kolmogrov-Smirnov ميانگين تغييرات متغيرهاى كمى داخل كروهها از آزمون Paired t- test تغييرات گروهها از آزمون ANOVA و براى مقايسههاى زوجى در صورت معنادار بودن از تست تعقيبى توكى

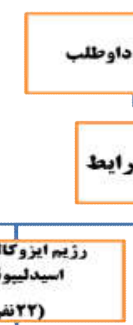

I

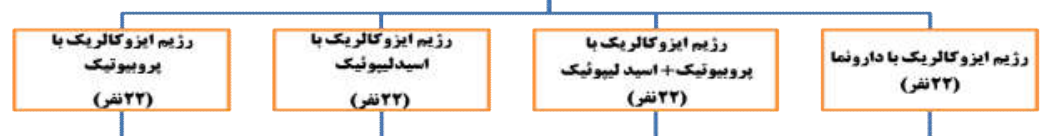

r
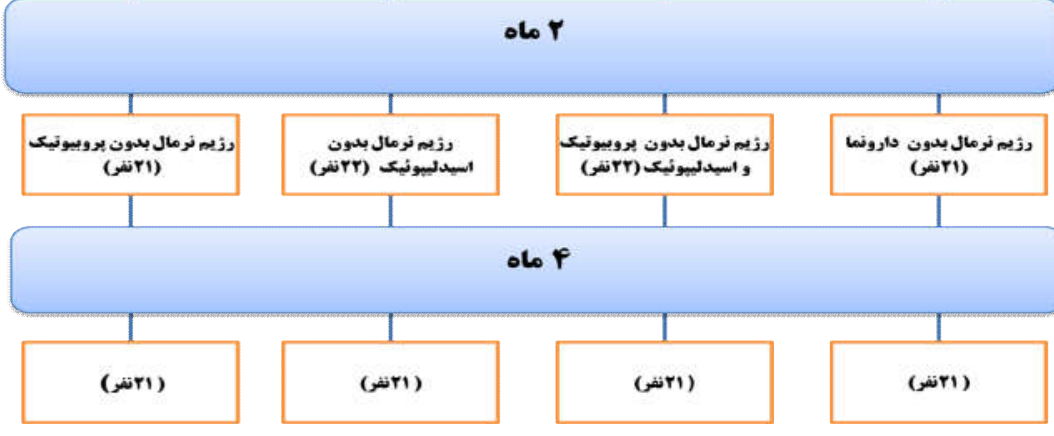

olof
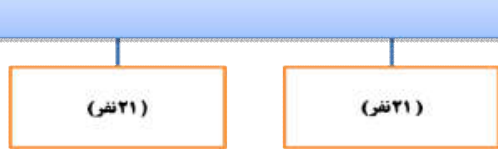

شكل ا. فلوجارت يخوهش و نحوهى تخصيص نمونه ها به كروه هاى مداخله و دارونما

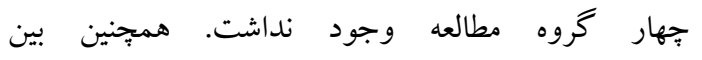
شركت كنند گان \& كروه در ابتداى مطالعه از لحاظ وزن، BMI دور كمر، جربى بدن، CRP و فعاليت بدنى اختلاف
تجزيهوتحليل نهايى بر روى دادههاى NF نفر كه مطالعه را به كامل كردند انجام شد. ميانگين سنى شركت كنند

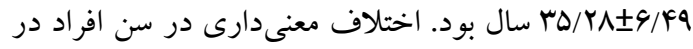


مطالعه گزارشى از اثرات نامطلوب درباره مصرف مكملها و يا دارونما از شركت كنند كان دريافت نشد.
معنىدارى وجود نداشت. مشخصات شركت كنند گان در ابتداى يُزوهش در جدول شماره ا بيان شده است. در اين

جدول ا. ميانكين و انحراف معيار شاخصهاى تنسنجى و فاكتور التهابى افراد در ابتداى مطالعه در كروههاى مداخله و كنترل

\begin{tabular}{|c|c|c|c|c|c|}
\hline P-value* & 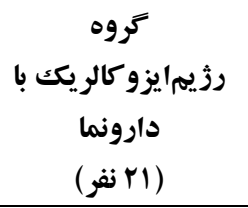 & 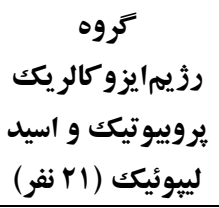 & 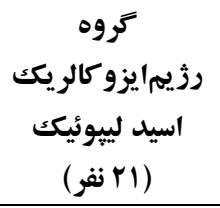 & 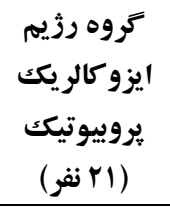 & متغير ها \\
\hline$\cdot / 419$ & $M F / Y q \pm V / r \Delta$ & $r F / \wedge G \pm \Delta / N r$ & $r V / r r \pm V / q A$ & $r F / 9 \mathrm{~V} \pm \Delta / \cdot r$ & سن (سال) \\
\hline.$/ 914$ & $V F / V I \pm q / F r$ & $V F / Y F \pm \| I / F \Delta$ & $\mathrm{VH} / \wedge 9 \pm \mathrm{V} / \cdot \mathrm{V}$ & $\vee \mathrm{V} / 9 \Lambda \pm V / \Lambda 9$ & وزن (كيلوكرم) \\
\hline$\cdot / 419$ & $Y V / A V \pm \cdot / \Delta I$ & $r V / V \Lambda \pm \cdot / 9 \Lambda$ & $r V / r q \pm \cdot / \Delta V$ & $r V / \Delta V \pm \cdot / V V$ & 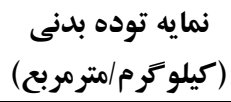 \\
\hline$\cdot / A \cdot F$ & $19 \Delta / \Gamma \wedge \pm 9 / \Gamma \Gamma$ & $19 \pi \pm 1 \cdot / \mathrm{Ar}$ & $194 / 9 \cdot \pm 9 / 194$ & $19 \mu / 4 \Delta \pm \mathrm{V} / \mathrm{r}$. & قد (سانتىمتر) \\
\hline$\cdot / r \cdot 4$ & $1 \cdot V / Y q \pm 1 / r \Lambda$ & $1.9 / \pi r \pm 1 / .9$ & $1.9 / \mathrm{VV} \pm \cdot / \mathrm{VI}$ & $1 \cdot \Delta / V \Delta \pm I / F F$ & $\begin{array}{c}\text { دور كمانتى متر) } \\
\end{array}$ \\
\hline$\cdot / 4 \cdot V$ & $M Y / F 9 \pm \cdot / V V$ & $r \mid / \Delta V \pm \cdot / 91$ & $M I / \Delta F \pm \cdot / \Lambda$. & $r \mathrm{r} / \mathrm{V} \pm \cdot / q r$ & درصد جربى بدن \\
\hline$\cdot / \Delta V^{F}$ & $1 \cdot / \wedge 9 \pm \cdot / \mathrm{VV}$ & $1 \cdot / 99 \pm \cdot / V V$ & 1./99E./Ar & $1 \cdot / V \Delta \pm \cdot / A r$ & $\begin{array}{c}\text { Cي يروتئين واكنشى } \\
(\mu \mathrm{M})\end{array}$ \\
\hline$\cdot / \Delta \Lambda \mid$ & $r G / r \cdot \pm r / v \Delta$ & $r q / 10 \pm r / 99$ & $r q / F r \pm Y / \Lambda q$ & $r V / r V \pm r / V \Lambda$ & فعاليت فيزيكى (مت /هفه) \\
\hline.$/ 1 \cdot 9$ & $11 / / 4 \cdot \pm 1 / 94$ & $111 / 9 \cdot \pm 1 / 99$ & $119 / 19 \pm 1 / 99$ & $11 V / r 9 \pm Y / 9$. & 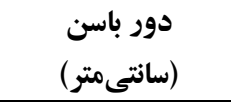 \\
\hline
\end{tabular}

ANOVA بقبر اساس آزمون آمارى

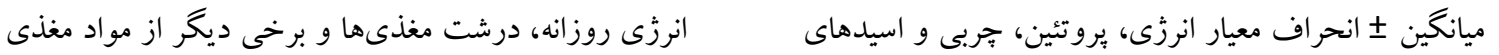

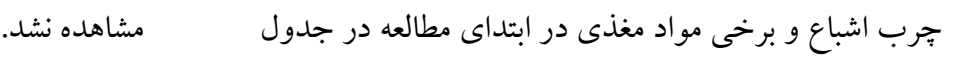
شماره Y T آورده شده است. اختلاف معنىدارى در دريافت 
^ براسى تاثير مكمل...

جدول r. مقايسه ميانكين و انحر اف معيار دريافت روزانه كالرى، درشت مغذىها و برخى ريزمغذىها در كروههاى مورد مطالعه در ابتداى مطالعه

\begin{tabular}{|c|c|c|c|c|}
\hline P-value* & 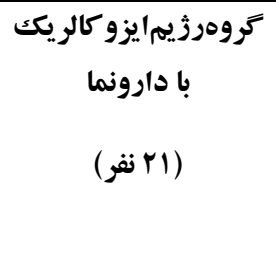 & 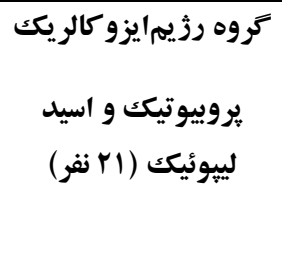 & 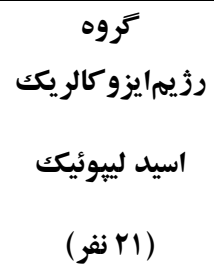 & 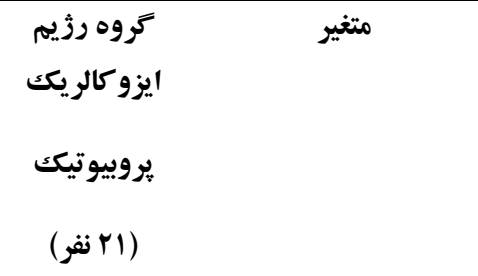 \\
\hline.$/ 4 q$ & $19 \cdot 1 / 11 \pm r \cdot \cdot / \cdot r$ & $119 \cdot / \cdot v \pm 191 / 9$ & $|\wedge r q \pm| q r / .9$ & انرخى (كيلو كالرى) \\
\hline.$/ 011$ & $r \Delta F / / F \pm F V / \Lambda$ & $r \Delta Y / 19 \pm r \cdot / q 1$ & $r F G / 11 \pm F V / r T$ & 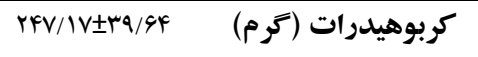 \\
\hline$\cdot / A \cdot r$ & $V Y / \cdot F \pm|F / r|$ & $V Y / \cdot F \pm|F / Y|$ & GN/ITIII/TD & يروتئين (كرم) \\
\hline .191 & $99 / 1 \mathrm{~V} \pm \mathrm{V} / 9 \mathrm{r}$ & $94 / Y F \pm \Lambda / \cdot F$ & $9 Y / 11 \pm \wedge / 19$ & هربى (كرم) \\
\hline$\cdot / 4 V I$ & $r Y / / 9 \pm Y / \cdot \Lambda$ & $r \mu / r \pm \Psi / \mu 1$ & $r \cdot \pm r / \Delta q$ & ( \\
\hline$\cdot / 0 \cdot V$ & $9 V / Y| \pm| q / 4 \mid$ & $9 N / 10 \pm 1 V / 19$ & $9 \Delta / 9 r \pm r \cdot / \cdot 9$ & ويتامين ث (ميلى \\
\hline ./MYG & $9 / r \mu \pm 1 / 19$ & $\Lambda / 91 \pm \cdot / V F$ & $9 / \cdot 1 \pm \cdot / A V$ & ويتامين E) \\
\hline $.191 \mathrm{~V}$ & $\mid r \cdot / 19 \pm r V / \Delta 1$ & $119 / 9 \Delta \pm \mu 1 / \cdot 4$ & $|r \cdot /| V \pm r q / \mu \mid$ & سلنيوم (ميكروكرم) \\
\hline بت فيزيكى مطالعه & 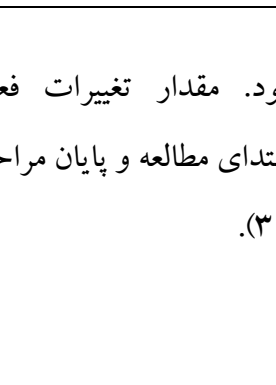 & شر كت كنى مارونما معنى مار & 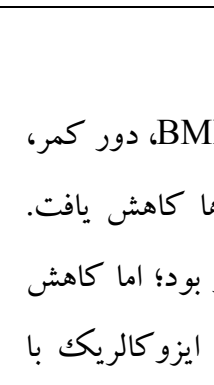 & 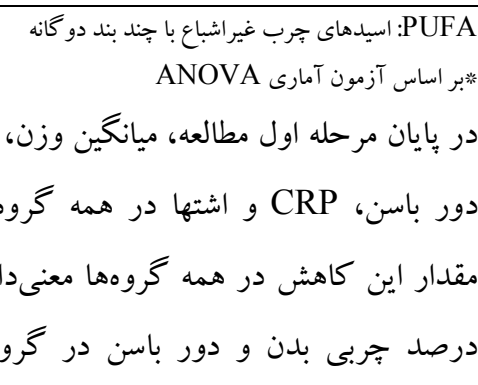 \\
\hline
\end{tabular}


9 هسين خادم همَيقيان

جدول זّ. مقايسه تغييرات ميانكين و انحر اف معيار شاخصهاى تنسنجى و فاكتور التهابى افراد در ابتداى مطالعه در كروههاى مداخله و كنترل در يايان مرحله اول سكائ

\begin{tabular}{|c|c|c|c|c|c|c|c|}
\hline \multirow[t]{3}{*}{ P-value* } & روه رذيم & رذيم & كروه & تروه رزيم & \multirow{3}{*}{ 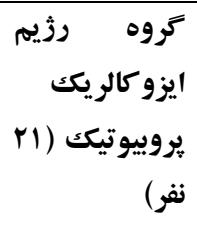 } & \multirow{3}{*}{\multicolumn{2}{|c|}{ متغيرها }} \\
\hline & ايزو كالريك & \multirow[b]{2}{*}{ اسيد } & \multirow{2}{*}{ 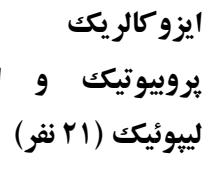 } & ايزوكالريك & & & \\
\hline & 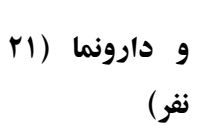 & & & 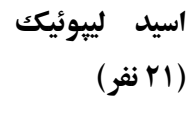 & & & \\
\hline.$/ 914$ & $V F / V I \pm q / F r$ & & $V F / Y F \pm 11 / F \Delta$ & $V / \wedge 9 \pm V / \cdot V$ & $\vee \Gamma / 9 \wedge \pm V / \Lambda 9$ & ابتدا & \\
\hline.$/ \cdot \mu \Lambda$ & $V Y / Q r \pm V / r r$ & & GN/VYEG/YM† & $V \cdot / F I \pm V / r r$ & $99 / V F \pm V / . r \dagger$ & بعد از دو ماه & وزن \\
\hline &.$/ \cdot k r$ & &.$/ \cdot 1$ & .1 .44 & $\% \mathrm{YV}$ & $\mathrm{P}$-value** & \\
\hline & $-I / V \wedge \pm Y / Y$ & & $-Q / \Delta Y \pm Y / Y Y$ & $-r / f \Delta \pm 1 / 19$ & $-r / 9 f \pm \cdot / \wedge r$ & ميانگين تغييرات & \\
\hline$\cdot / 419$ & $Y V / A V \pm \cdot / \Delta 1$ & & $r V / V \Lambda \pm \cdot / q \Lambda$ & $Y V / Y G \pm \cdot / \Delta V$ & $Y V / \Delta V \pm \cdot / V V$ & ابتدا & \\
\hline$\cdot|\cdot Y|$ & $r 4 / 99 \pm \cdot / r q$ & & $r \Delta / V Y \pm \cdot / F I \dagger$ & $r \Delta / q \Lambda \pm \cdot / 1 r$ & $r \& / 1 \pm \cdot / \cdot \Lambda$ & بعد از دو ماه & شاخص \\
\hline &.$/ \cdot F r$ & &.$/ .14$ & س &.$/ \cdot r$ & P-value & \\
\hline & $-I / Y I \pm \cdot / Y Y$ & & $-Y / \cdot 9 \pm \cdot / 0 V$ & $-I / Y \Lambda \pm \cdot / F F$ & $-1 / 4 V \pm \cdot / 99$ & ميانگين تغييرات & \\
\hline$\cdot / r \cdot F$ & $1 \cdot V / Y G \pm 1 / Y \Lambda$ & & $1.9 / \pi r \pm 1 / .9$ & $1.9 / \mathrm{V} \pm \cdot / \mathrm{NI}$ & $1 \cdot \Delta / V \Delta \pm I / F F$ & ابتدا & \\
\hline$\cdot / \cdot r V$ & $1 \cdot \Delta / 9 \Delta \pm 1 / \Delta \Lambda$ & & $1 \cdot 1 / 9 . \pm 1 / 11 \dagger$ & $1 . F / N \pm \pm / N G$ & 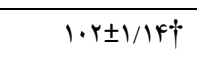 & بعد از دو ماه & دور كمر \\
\hline & $.1 .4 \Lambda$ & &.$/ \cdots 1$ & .1 .49 & $\%$ \% & P-value & \\
\hline & - & & $-F / V \Psi \pm \cdot / V \Delta$ & $-r / 9 \Psi \pm \cdot / \cdot \Delta$ & $-r / N \Delta \pm \cdot / r$. & ميانخين تغييرات & \\
\hline$\cdot / 4 \cdot v$ & $r Y / F 9 \pm \cdot / V V$ & & $r / / \Delta V \pm \cdot / 91$ & $M I / \Delta F \pm \cdot / A$. & $r \mathrm{r} / \mathrm{V} \pm \cdot / 9 \mu$ & |بتدا & \\
\hline$\%$ & $\mathrm{rI/FV} \pm \cdot / \mathrm{VA}$ & & $r N / I Y \pm 1 / \cdot 1 \dagger$ & $r \cdot / \kappa \Psi \pm \cdot / V F$ & $r q / \cdot \cdot \pm \cdot / q r$ & بعد از دو ماه & درصد جربى بدن \\
\hline & $.1 .9 \mathrm{~V}$ & & .1 .19 &.$/ . \mathrm{Fr}$ &.$/ .49$ & P-value & \\
\hline & $\cdot / 9 \pm \cdot / \cdot 1$ & & $-r / 4 F \pm / \cdot 1$ & $-1 / 11 \pm \cdot / \cdot 9$ & $-Y / \cdot V \pm \cdot / \cdot 1$ & ميانخين تغييرات & \\
\hline$\cdot / \Delta V F$ & $1 \cdot / 19 \pm \cdot / \mathrm{VV}$ & & $1 \cdot / 99 \pm \cdot / \mathrm{VV}$ & $1 \cdot 199 \pm \cdot / \mathrm{Ar}$ & $1 \cdot / N \Delta \pm \cdot / A r$ & ابتدا & \\
\hline .1 .18 & $9 / 94 \pm \cdot / V \Lambda$ & & $V / \cdot r \pm \cdot / v \Lambda \dagger$ & 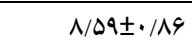 & V/AVE./MYT & بعد از دو ماه & يروتئينى \\
\hline &.$/ \cdot \mu \Lambda$ & &.$/ \cdots 1$ & .1 .19 &.$/ \cdot 1$ & P-value & \\
\hline & $-1 / Y Y \pm \cdot / \cdot 1$ & & $-r / 99 \pm \cdot / \cdot 1$ & $-r / \cdot V \pm \cdot / \cdot r$ & $-r / \Lambda \Lambda \pm \cdot / \Delta r$ & ميانخين تغييرات & \\
\hline
\end{tabular}

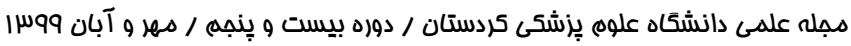




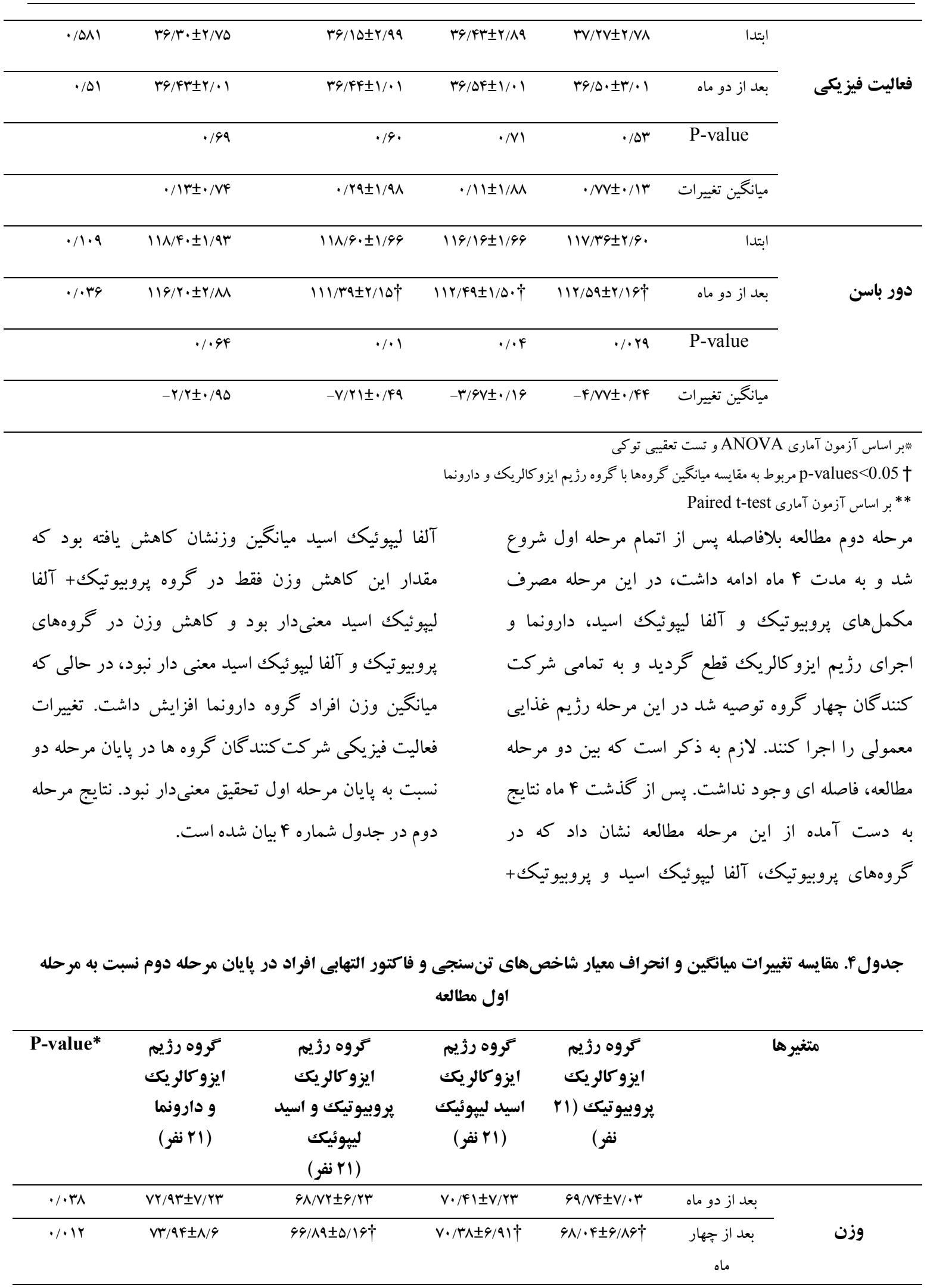


هسين فادم دمَيقيان

\begin{tabular}{|c|c|c|c|c|c|c|}
\hline & $\cdot / \cdot 11$ & .1 .49 & $\cdot / A F$ &.$/ \cdot v^{r}$ & P-value ** & \\
\hline & $1 / \cdot 1 \pm 1 / 4 r$ & $-Y / I V \pm I / \cdot V$ & $-\cdot / r \cdot \pm \cdot / \mu r$ & $-I / V \pm \cdot / Y V$ & ميانگين & \\
\hline & & & & & ت تغييرات & \\
\hline$\cdot / \cdot r I$ & $r 9 / 99 \pm \cdot / r 9$ & $r \Delta / V Y \pm \cdot / F I$ & $r \Delta / Q \Lambda \pm \cdot / R$ & $r 9 / 1 \pm \cdot 1 \cdot 1$ & بعد از دو ماه & \\
\hline \multirow[t]{5}{*}{$\cdot / \cdot+4$} & $r V / \cdot r \pm \cdot / q r$ & $r \Delta / \cdot r \pm 1 / r q \dagger$ & $r \Delta / 9 V \pm \cdot / V F \dagger$ & $r \Delta / \& G \pm \cdot / V \Delta \dagger$ & بعد از جهار & شاخص توده بدنى \\
\hline & & & & & ماه & \\
\hline & $.1 \cdot 9$ & $\cdot / \cdot V^{F}$ & 每 & $\cdot / \cdot \wedge$ & P-value & \\
\hline & $\cdot / r V \pm \cdot / \mu q$ & $-\cdot / 99 \pm \cdot / 91$ & $\cdot 1 \cdot 1 \pm \cdot 191$ & $-.194 \pm .19 \mathrm{~V}$ & ميانگين & \\
\hline & & & & & تغييرات & \\
\hline.$/ \cdot M V$ & $1 \cdot \Delta / 9 \Delta \pm 1 / \Delta \Lambda$ & $1 \cdot 1 / 9 \cdot \pm 1 / 11$ & $1 \cdot F / 1 r \pm \cdot / V q$ & $1 \cdot Y \pm I / / F$ & بعد از دو ماه & \multirow{6}{*}{ دور كمر } \\
\hline \multirow[t]{5}{*}{$\cdot / \cdot r l$} & $1 \cdot \Delta / \pi r \pm 1 / \lambda$ & $1 \cdots / 4 \wedge \pm / 1 / 9 \wedge \dagger$ & $1 \cdot r / 4 r \pm \cdot / v q$ & $1 . r / .9 \pm 1 / 11 \dagger$ & بعد از جهار & \\
\hline & & & & & ماه & \\
\hline &.$/ / F$ & .1 .91 &.$/ .9 V$ & $\cdot / \mathrm{NI}$ & P-value & \\
\hline & $\cdot 19 Y \pm \cdot / Y Y$ & $-1 / 1 r \pm \cdot / 1 r$ & $-\cdot / \mathrm{V} \pm \cdot / \cdot r$ & $.1 \cdot 9 \pm \cdot 1 \cdot r$ & ميانگين & \\
\hline & & & & & تغييرات & \\
\hline.$/ \cdot \pi$ & $\Gamma I / F V \pm \cdot / V \Lambda$ & $r N / I r \pm 1 / \cdot 1$ & $r \cdot / k r \pm \cdot / V F$ & $r q / \cdot \cdot \pm \cdot / q r$ & بعد از دو ماه & \multirow{6}{*}{ درصد جربى بدن } \\
\hline \multirow[t]{5}{*}{.$/ \cdot F r$} & $r \cdot / 9 Y \pm \cdot / \wedge F$ & $r N / \cdot Y \pm 1 / r+T$ & $r Q / \Delta l \pm \cdot / N r$ & $r V / 99 \pm \cdot / 91 \dagger$ & بعد از جهار & \\
\hline & & & & & ماه & \\
\hline & $\cdot / \cdot \wedge F$ & .1 .9 & $\cdot / \cdot \mathrm{WV}$ &.$/ \cdot m v$ & P-value & \\
\hline & $-\cdot / \Delta \Delta \pm \cdot / 9$ & $-\cdot / 11 \pm \cdot / \cdot r$ & $-\cdot / \Delta Y \pm \cdot / \cdot 1$ & $-1 / \cdot 1 \pm \cdot / \cdot 1$ & ميانگين & \\
\hline & & & & & ت تغييرات & \\
\hline.$/ \cdot 1 V$ & $q / q 4 \pm \cdot / V \Lambda$ & $V / \cdot r \pm \cdot / v \Lambda$ & $\Lambda / \Delta ৭ \pm \cdot / \wedge q$ & $V / \wedge V \pm \cdot / r r$ & بعد از دو ماه & \multirow{6}{*}{ يروتئينى واكنشى } \\
\hline \multirow[t]{5}{*}{.$/ \cdot 1$} & $9 / \mathrm{VI} \pm / V q$ & $\mathrm{~V} \pm \cdot / 91 \dagger$ & $\Lambda / F Y \pm \cdot / \Lambda \Delta$ & $V / \Delta F \pm \cdot / r V \dagger$ & بعد از جهار & \\
\hline & & & & & ماه & \\
\hline &.$/ 49$ & $\cdot / A r$ &.$/ 9 V$ & .101 & $\mathrm{P}$-value & \\
\hline & $-\cdot / r V \pm \cdot / \cdot r$ & $-\cdot / \cdot r \pm \cdot / / V$ & $-\cdot / 1 \mathrm{~V} \pm \cdot / \cdot 1$ & $-\cdot / \mu^{\prime} \pm \cdot / \cdot \Delta$ & ميانگين & \\
\hline & & & & & تغييرات & \\
\hline.$/ \cdots 1$ & $\wedge 9 / \cdot 9 \pm 1 / \cdot r$ & $\Lambda \Gamma / \wedge \Lambda \pm \cdot / \vee \wedge$ & $\Lambda \Delta / \cdot Y \pm \cdot / V \Delta$ & $\Lambda F / 9 \cdot \pm 1 / \Lambda \Lambda$ & بعد از دو ماه & \multirow{6}{*}{ فشارخوندياستولى } \\
\hline \multirow[t]{5}{*}{$<\cdot / \cdots 1$} & $\wedge q / / f \pm 1 / \cdot 1$ & $\Lambda Y / N \Psi \pm \cdot / 94 \dagger$ & $\Lambda F / Y \Delta \pm \cdot / 99 \dagger$ & $\Lambda F / M G \pm 1 / 10 \dagger$ & بعد از جهار & \\
\hline & & & & & ماه & \\
\hline & $\cdot / M$ & $\cdot / \Delta 1$ & $\cdot / q \mu$ & $.19 \mathrm{~V}$ & P-value & \\
\hline & $\cdot / \cdot \Delta \pm \cdot / \cdot r$ & $-\cdot / 4 \Delta \pm \cdot / 1 \wedge$ & $-\cdot / V V \pm \cdot / \cdot 9$ & $-\cdot / r F \pm \cdot / \cdot r$ & ميانگين & \\
\hline & & & & & تغييرات & \\
\hline$<\cdot / \cdots)$ & $1 r V / \cdot r \pm 1 / 9 V$ & $|r| / r \cdot \pm r / 90$ & $\mid r \Delta / \Delta T \pm 1 / r \Delta$ & $|r r / 9 \Delta \pm r /| \mid$ & بعد از دو ماه & \multirow{4}{*}{ فشارخونسيستولى } \\
\hline \multirow[t]{3}{*}{$<\cdot / \cdot \cdot 1$} & $|r V / \Delta| \pm 1 / 9$ & $\mid r \cdot / \Lambda \Lambda \pm r / 94 \dagger$ & $\mid r \Delta / I V \pm I / r \Lambda \dagger$ & $\mid r r / Y G \pm r / g \Psi \dagger$ & بعد از جهار & \\
\hline & $\cdot / \mathrm{WV}$ & $\cdot 109$ &.$/ 90$ & $\cdot 19$ & P-value & \\
\hline & $\cdot / \cdot \nvdash \Lambda \pm \cdot / \cdot V$ & $-\cdot / 4 Y \pm \cdot / \cdot 1$ & $-\cdot / r 9 \pm \cdot / 1 r$ & $-\cdot / r q \pm \cdot / \uparrow \wedge$ & ميانگين & \\
\hline
\end{tabular}

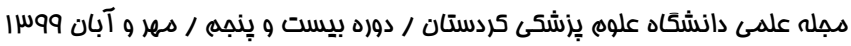




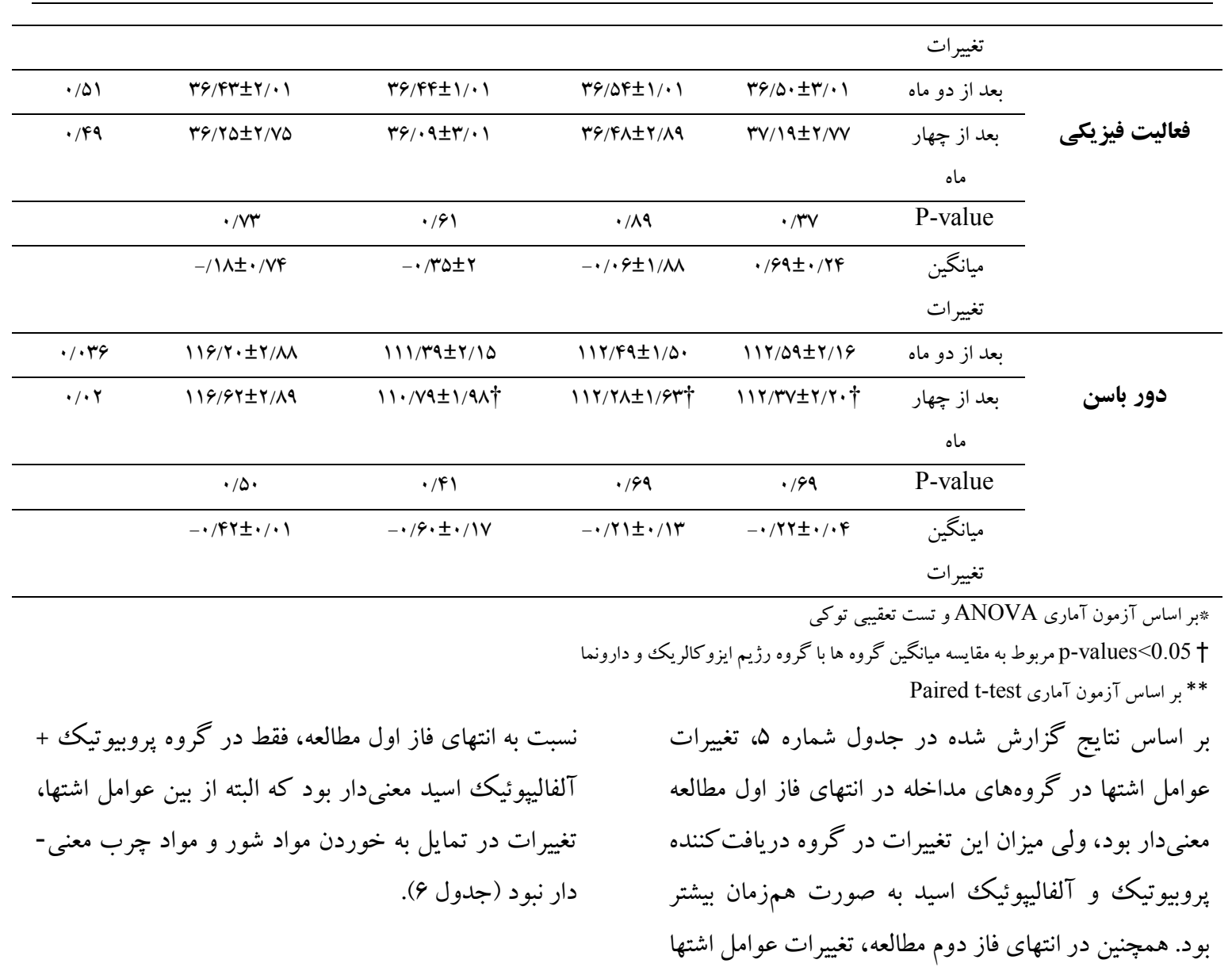

جدول ه. مقايسه تغييرات ميانغين و انحراف معيار اشتهاى افراد در يايان مرحله اول نسبت به شروع مطالعه

\begin{tabular}{|c|c|c|c|c|c|c|}
\hline P-value* & كروه دارونما & 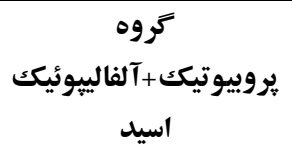 & آلفا ليهيويكك & يروبيوتيكى & & متغير \\
\hline r & $V / r Y \pm r / \cdot r$ & $\Lambda / \Delta \pm r / \cdot V$ & $V / a r \pm 1 / \cdot V$ & $V / F r \pm I / r r$ & قبل مطالعه & كر سنغى \\
\hline \multirow[t]{3}{*}{$. / \cdot Y \mid$} & $V / \Lambda I \pm Y / I V$ & $\Delta / 19 \pm \cdot / 4 \mid \dagger$ & $4 \pm \cdot / V^{\prime} \dagger$ & $9 / \cdot 4 \pm \cdot / 91 \dagger$ & انتهاى فاز اول & \\
\hline & .109 &.$/ \cdots 1$ & . &.$/ 4$ & P-value ** & \\
\hline & $\cdot / \Delta Q \pm \cdot / / F$ & $-r / \Gamma \mid \pm 1 / 99$ & $-1 / 9 r \pm \cdot / \mathrm{V}$ & $-1 / \sim q \pm \cdot / r r$ & اختلاف & \\
\hline .1 .9 & 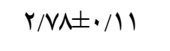 & $r / l \Delta \pm \cdot / T$ & $r / \cdot V \pm \cdot / q r$ & $r / \Delta V \pm \cdot / \kappa Y$ & قبل مطالعه & احساس يرى \\
\hline \multirow[t]{3}{*}{.$/ . r$} & $Y /|q \pm \cdot / F|$ & $\varphi / \Lambda \mid \pm \cdot / \Delta Q \dagger$ & $r \pm \cdot / 9 \mu \dagger$ & r/৭४ $\pm \cdot / . ৭ \uparrow$ & انتهاى فاز اول & \\
\hline & $\cdot / \Delta \Lambda$ &.$/ \cdots 1$ & ( &.$/ \cdot r q$ & P-value & \\
\hline & $-/ \Delta 9 \pm \cdot / r$ & $\mathrm{r} / 99 \pm \cdot / \mathrm{FV}$ & $1 / 94 \pm \cdot / r$ & $1 / \mu q \pm \cdot / \mu$ & اختلاف & \\
\hline$\cdot|4|$ & $V / 99 \pm Y / \uparrow r$ & $\Lambda / Y \Lambda \pm Y / \Delta F$ & $\Lambda \pm r / \cdot 1$ & $\Lambda / F \pm r / r q$ & قبل مطالعه & تمايل به \\
\hline \multirow[t]{2}{*}{$\% \cdot r F$} & $\Lambda / \cdot V \pm r / 99$ & $\Delta / 9 Y \pm 1 / \cdot V \dagger$ & $G / V F \pm r / / r$ & $9 / 11 \pm r / 19$ & انتهاى فاز اول & خوردن \\
\hline &.$/ 94$ &.$/ \cdot r$ &.$/ . Y 9$ & $\%$ ro & P-value & \\
\hline
\end{tabular}




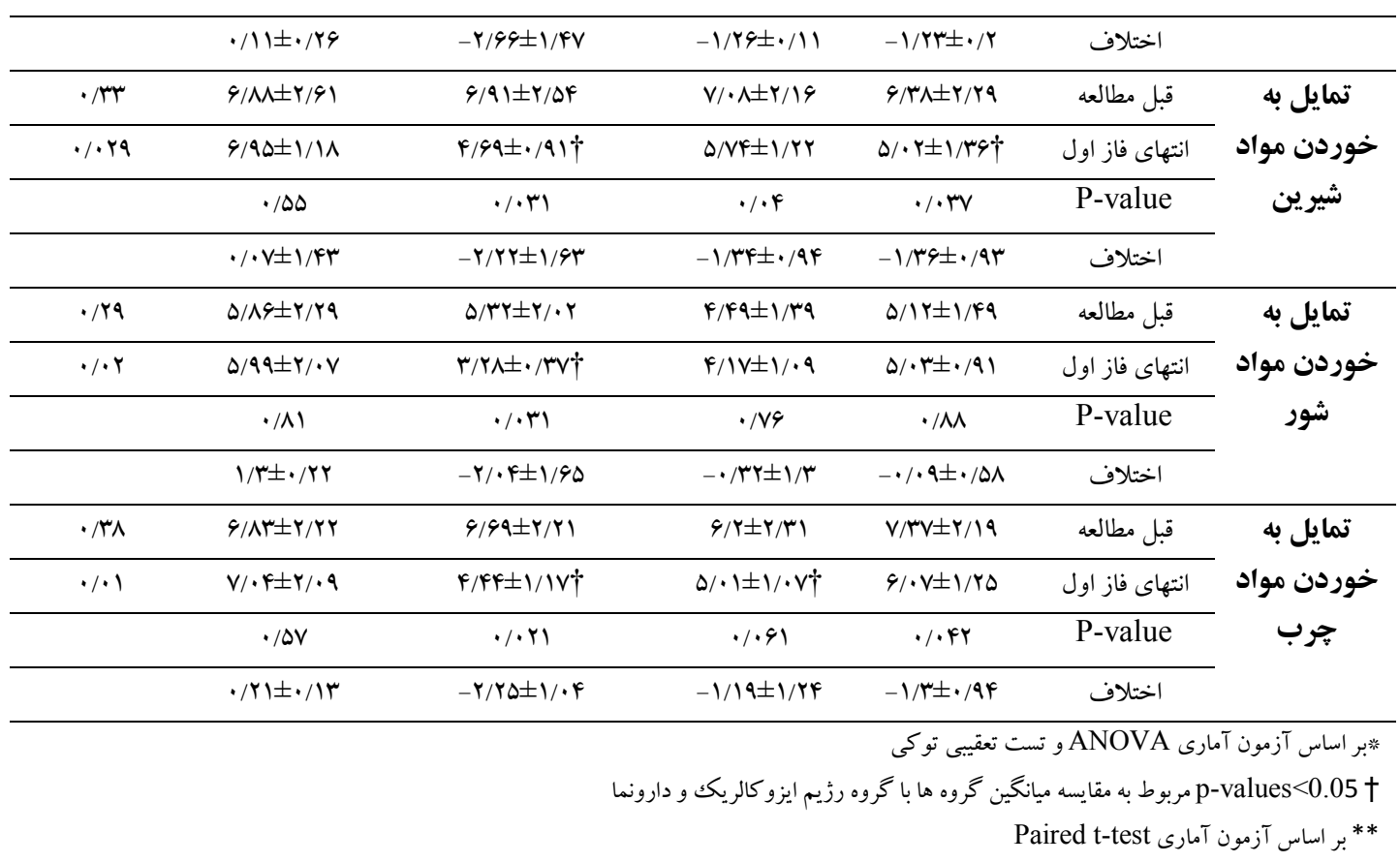

جدول و. مقايسه تغييرات ميانغين و انحراف معيار اشتهاى افراد در هايان فاز دوم نسبت به هايان فاز اول مطالعه

\begin{tabular}{|c|c|c|c|c|c|c|}
\hline P-value* & كروه هيلاسبو & 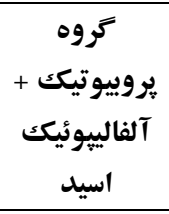 & لييوئيك اسيد آلفا & يروبيوتيك & & \\
\hline. $\mid \cdot Y$ & $V / \Lambda I \pm Y / / V$ & $\Delta /|q \pm \cdot / 4|$ & $4 \pm \cdot / r V$ & $9 / \cdot 4 \pm \cdot / 91$ & انتهاى فاز اول & كرسنكى \\
\hline \multirow[t]{3}{*}{$\cdot / \cdot Y I$} & $V / ৭ ৭ \pm r / r q$ & $r / \cdot r \pm \cdot / \mu r \dagger$ & $\Delta / ৭ \pm \cdot / V \Psi \dagger$ & $\Delta / a r \pm \cdot / \wedge V^{\dagger}$ & انتهاى فاز دوم & \\
\hline & $\cdot / V^{F}$ &.$/ \cdot \mu \Lambda$ & $\cdot / A Y$ &.$/ 01$ & P-value ** & \\
\hline & $\cdot / \Lambda \pm \cdot / r$ & $-1 / 19 \pm \cdot / \cdot V$ & $-\cdot / 1 \pm \cdot / \mu^{4}$ & $-\cdot / 11 \pm \cdot / \cdot \varphi$ & اختلاف & \\
\hline.$/ . r$ & $r /|q \pm \cdot / 4|$ & $F / A \mid \pm \cdot / \Delta 9$ & $r \pm \cdot / 9 r$ & $r / 99 \pm \cdot / \cdot 9$ & انتهاى فاز اول & \multirow[t]{4}{*}{ احساس بوى } \\
\hline \multirow[t]{3}{*}{.$/ \cdot r$} & $Y / \cdot \mid \pm \cdot / V 1$ & $\Delta / 9 V \pm \cdot / 91 \dagger$ & $\varphi / \Lambda \pm \cdot / \mu q \dagger$ & $\varphi / \cdot V \pm \cdot / r \Delta \dagger$ & انتهاى فاز دوم & \\
\hline & $\cdot / T F$ & .1 .49 & $\cdot / r V$ & $\cdot / \mu F$ & P-value & \\
\hline & $-\cdot / \cdot 9 \pm \cdot / r$ & $1 / 19 \pm \cdot / \cdot r$ & $\cdot / A \pm \cdot / Y F$ & $\cdot / 11 \pm \cdot / 19$ & اختلاف & \\
\hline$\% \cdot r F$ & $\Lambda / V \pm r / 99$ & $\Delta / 9 Y \pm 1 / \cdot V$ & $G / V F \pm Y / T Y$ & $9 / 1) \pm r / 19$ & انتهاى فاز اول & \multirow{4}{*}{ خوريل به } \\
\hline \multirow[t]{3}{*}{.$/ \cdot 1$} & $\Lambda / 99 \pm r / \cdot V$ & $\varphi / \cdot \wedge \pm 1 / 1 \uparrow \dagger$ & $9 / 4 \backslash \pm Y / 19 \dagger$ & 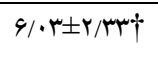 & انتهاى فاز دوم & \\
\hline & .191 &.$/ . r \Delta$ & .19 & .109 & P-value & \\
\hline & $\cdot / \Delta 9 \pm \cdot /{ }^{\prime} \wedge$ & $-1 / \Delta f \pm \cdot / \cdot f$ & $-\cdot / \mu \mathrm{r} \pm \cdot / \cdot \mathrm{V}$ & $-\cdot / v \wedge \pm \cdot / l F$ & اختلاف & \\
\hline.$/ . \mathrm{rq}$ & $9 / 9 \Delta \pm 1 / 1 \wedge$ & $f / 99 \pm \cdot / 91$ & $\Delta / V F \pm I / Y r$ & $\Delta / \cdot r \pm 1 / r q$ & انتهاى فاز اول & \multirow{4}{*}{ خوردن موايل به } \\
\hline \multirow[t]{3}{*}{.$/ \cdot 11$} & $V / .9 \pm Y / 9 \Lambda$ & $r / r Y \pm 1 / \mu \dagger$ & $\Delta / 1 \wedge \pm 1 / 91 \dagger$ & $F / \wedge \Delta \pm I / F \psi \dagger$ & انتهاى فاز دوم & \\
\hline & $\cdot / V^{\prime}$ &.$/ \cdot r v$ &.$/ 01$ &.$/ 49$ & P-value & \\
\hline & $\cdot / / f \pm 1 / \Delta$ & $-1 / F V \pm \cdot / I Y$ & $-\cdot / \Delta 9 \pm \cdot / \pi q$ & $-\cdot / \wedge 9 \pm \cdot / \cdot \wedge$ & اختلاف & \\
\hline
\end{tabular}

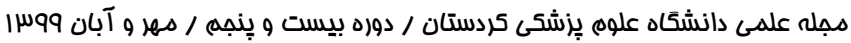


عار براسى تاثير هكمل ...

\begin{tabular}{|c|c|c|c|c|c|c|}
\hline$\cdot / \cdot r$ & $\Delta / ৭ ৭ \pm r / \cdot V$ & $r / Y \wedge \pm \cdot / r V$ & $\kappa / I V \pm 1 / \cdot q$ & $\Delta / \cdot r \pm \cdot / q 1$ & انتهاى فاز اول & تمايل به \\
\hline \multirow[t]{3}{*}{ 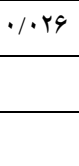 } & $9 / .9 \pm Y / Y \wedge$ & $r / r \mid \pm \cdot / F l \dagger$ & $r / \cdot \Delta \pm 1 / r q \dagger$ & $\Delta \pm 1 / \cdot r$ & انتهاى فاز دوم & خوردن مواد \\
\hline & $\cdot / \Delta \Lambda$ & D & $\cdot / 4 q$ & $\cdot / \Lambda r$ & P-value & شور \\
\hline & $\cdot /| \pm \cdot / Y|$ & $-\cdot / \cdot V \pm \cdot / \cdot r$ & $-\cdot / / r \pm \cdot / / V$ & $-\cdot / \cdot r \pm \cdot / \mu$ & اختلاف & \\
\hline.$/ \cdot 1$ & $V / \cdot r \pm r / \cdot q$ & $F / f F \pm 1 / / V$ & $\Delta / \cdot 1 \pm 1 / \cdot V$ & $\varphi / \cdot V \pm 1 / r \Delta$ & انتهاى فاز اول & تمايل به \\
\hline \multirow[t]{3}{*}{.$/ 1$} & $V \pm Y / F F$ & $r / 9 r \pm \cdot 199 \dagger$ & $f / 9 \pm 1 / 9 \dagger$ & $\Delta / V \Lambda \pm r / \cdot q$ & انتهاى فاز دوم & خوردن مواد \\
\hline & $\cdot / \wedge r$ & .1 .99 & .199 & $\cdot / D F$ & P-value & جرب \\
\hline & $-\cdot / \cdot \kappa \pm \cdot / r \Delta$ & $-\cdot / \Delta| \pm \cdot / \Delta|$ & $-\cdot / l \mid \pm \cdot / \Delta r$ & $-\cdot / \curlyvee q \pm \cdot / \wedge F$ & اختلاف & \\
\hline
\end{tabular}

ثقبر اساس آزمون آمارى ANOVA و تست تعقيبى توكى

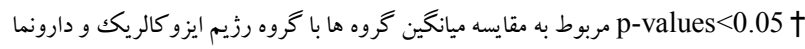

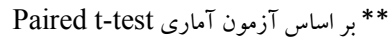

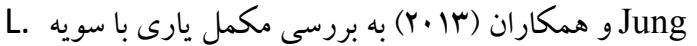

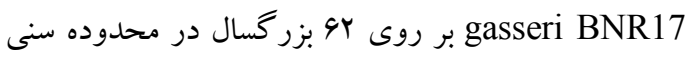
19 تا •و سال و با شاخص توده بدنى

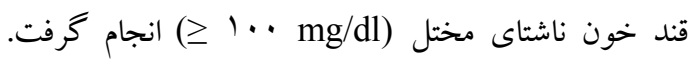

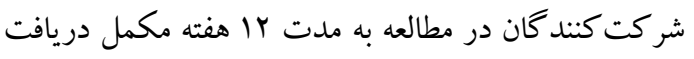

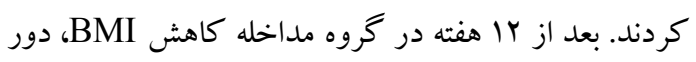

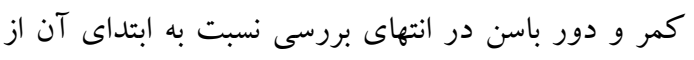

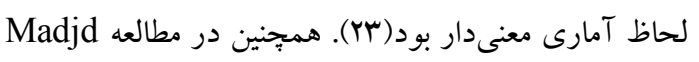

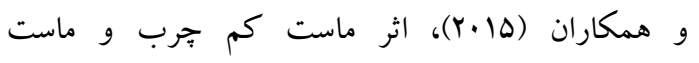
يروبيوتيكك در كاهش وزن زنان جاق تهران بررسى گرديد.

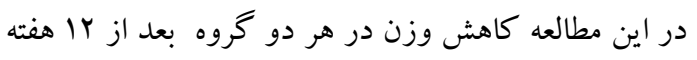

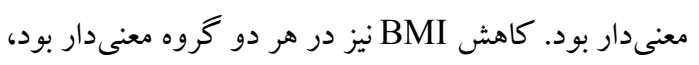

$$
\text { و اختلاف بين گروه ها معنىدار نبود (YF). }
$$

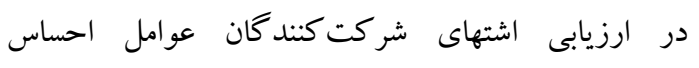
كرسنگگى، احساس برى، تمايل به خوردن مواد شيرين و و

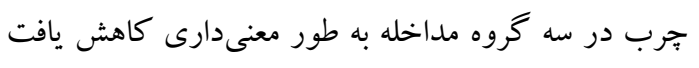

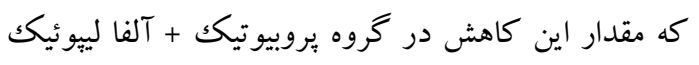

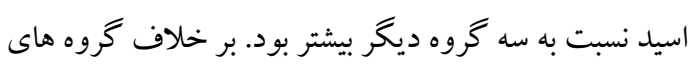

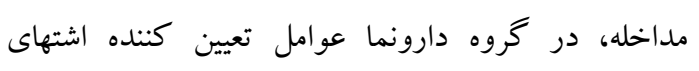

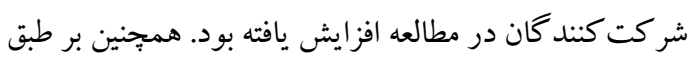
نتايج اين مطالعه، تغييرات كاهش وزن و كاهش اشتهاى افراد در خروههاى مداخله همسو بود ولى در خروه رزيم
مطالعه حاضر كه با هدف بررسى تأثير مكمل يارى

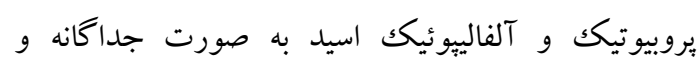

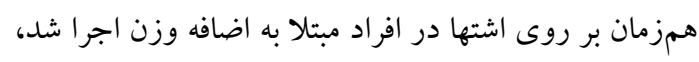

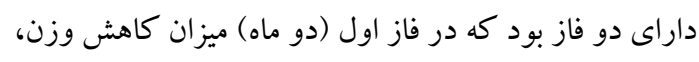
فاكتورهاى مربوط به آن و اشتها و در فاز دوم (جهار ماه)،

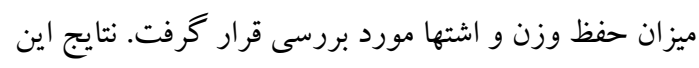
مطالعه بالينى نشان داد كه مكمل يارى يروبيوتيك و و آلفا

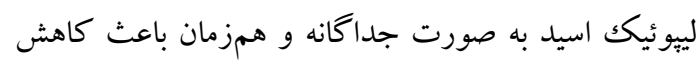
وزن، BMI، دور كمر و درصد جربى در بايان مرحله اول

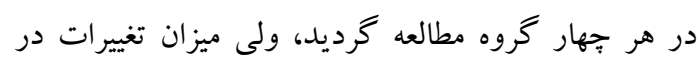

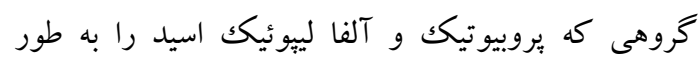

$$
\text { همزمان دريافت كرده بودند، بيشتر بود. }
$$

جاقى وضعيتى است كه در آن ميزان تعادل بين انرزى دردي

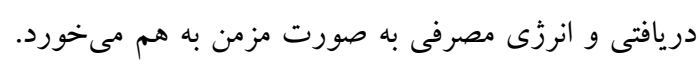

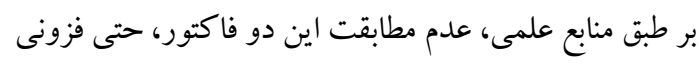

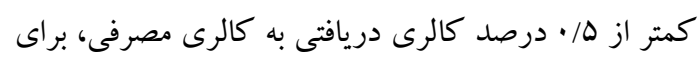

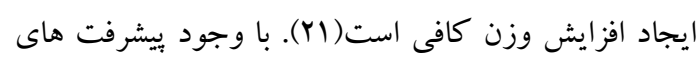

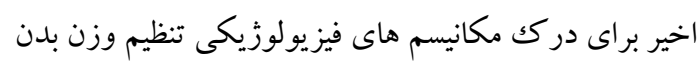

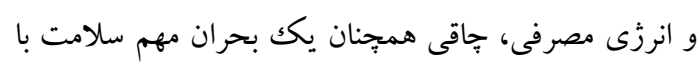

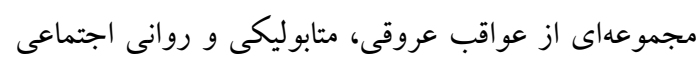

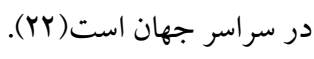


״رويّيونات) تبديل مى كند. اسيدهاى جرب با زنجيره كو تاه در شرايط متعددى مورد بررسى قرارگرفتهاند، و تأثير آنها بر سلامت ميزبان به خوبى مستند شده است(Y) SCFA هاى مشتق از ميكروبيوتايكك روده، به ويزه يروييونات، GPR41: G كزارش شده است كه از طريق فعال سازى protein-coupled receptors انترونو كرين، ترشح GLP-1 و قابلتوجهى افزايش مىدهد، كه باعث تحريك بيشتر بترون

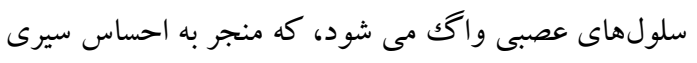

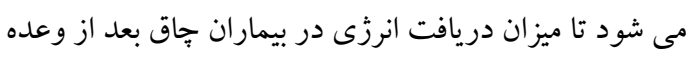

$$
\text { يكك غذايى كاهش يابد ·r). }
$$

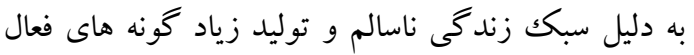

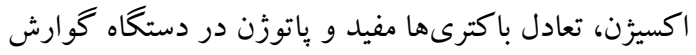

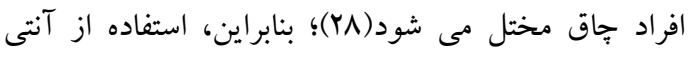

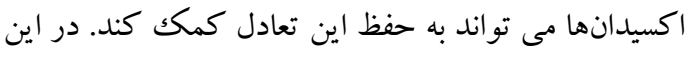

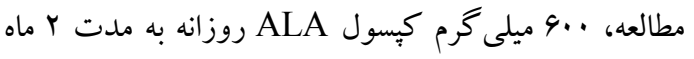

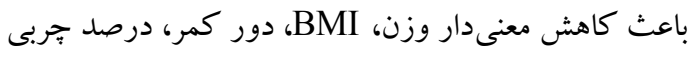

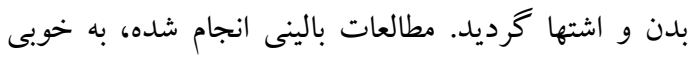
تأثير ALA در كاهش وزن در افراد داراى اضافه وزن و و جاق را گزارش كردهاند(N). نتايج دو مطالعه متآناليز نشان

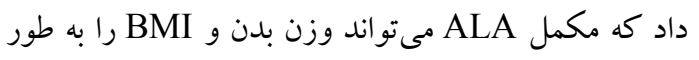

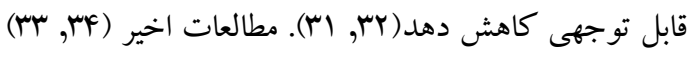

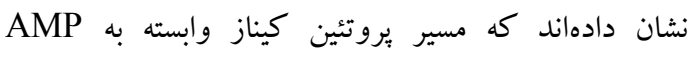
(AMP-activated protein kinase) مركزى مهم در تنظيم اشتها و مصرف انرزى بوده و ALA

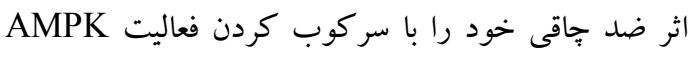

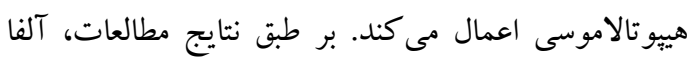

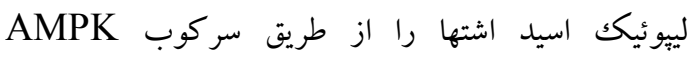
هييوتالاموس كاهش مىدهد(س/). در مطالعات انجام شده كالرى دريافتى در بيمارانى كه مكمل آلفا لييوئيك اسيد

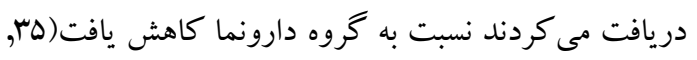

. ( $ه$
ايزو كالريكك با دارونما اخر جه كاهش وزن صورت گرفته معنىدار نبود ولى در مقابل اشتها و تمايل افراد به خوردن

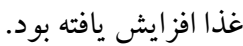
تنظيم اشتها نيز فر آيند يِيجيدهاى است كه شامل ارتباط بين

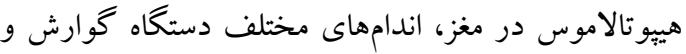
بافت جربى است(YD). حالت سيرى ممكن است با سيكُال

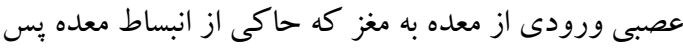

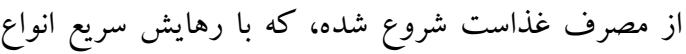

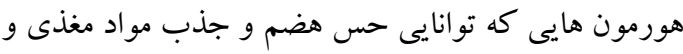

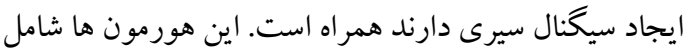

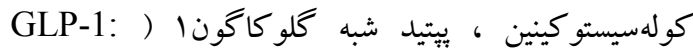
OXM: (Glucagon-like peptide 1 (PYY: Peptide YY) YY و يتيد (Oxyntomodulin

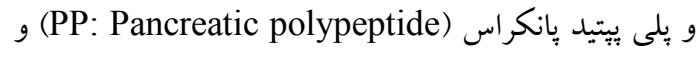
آميلين هستند. اين هورمونها به عنوان سيكنالهاى كوتاه بـاه

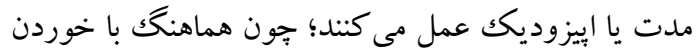
اتفاق مىافتند(Y)). وقتى تعادل در ميكروبيو تاى روده از بين

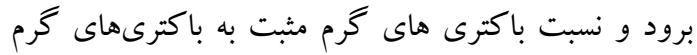

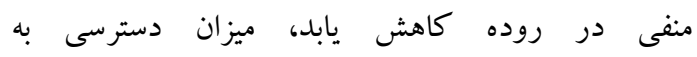
لييويلى ساكاريدها و ساير مولكولهاى بيش التهابى و انتقال

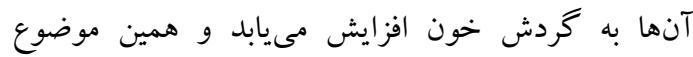

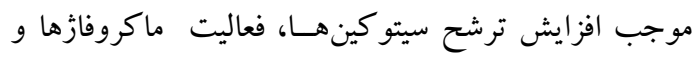

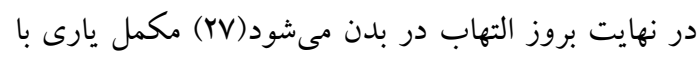

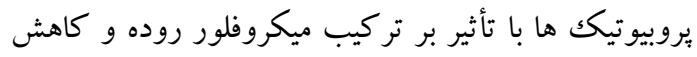

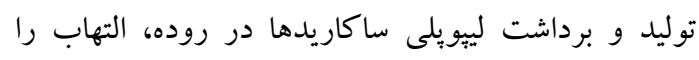

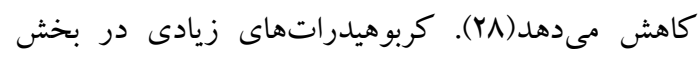

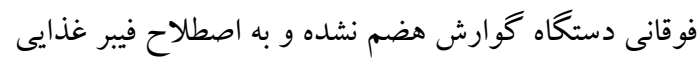
ناميده مىشوند. از اين رو، فيبرهاى غذايى به عنوان منبع انرزى توسط باكترىهاى خاص روده مورد استفاده قرار

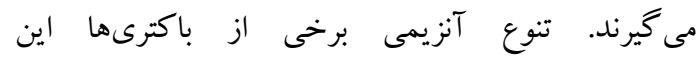

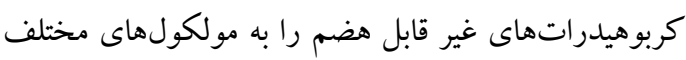

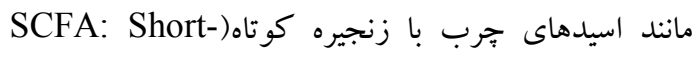
(براى مثال استات، بوتيرات و ونجيره (chain fatty acids 
يكى از نقاط قوت اين مطالعه، طراحى دو سو كور و دو

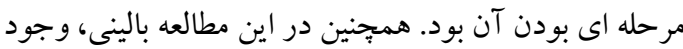

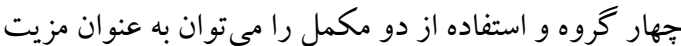
اين طرح در نظر گرفت. لازم به ذكر است كه اين مطالعه داراى محدوديتهايى همجون حجم نمونه بايين بود كه

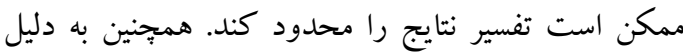

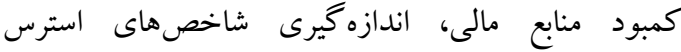
اكسيداتيو و همجنين ساير فاكتورهاى التهابى در اين مطالعه

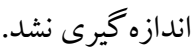

\section{نتيجه كيرى}

نتايج اين تحقيق نشان داد كه استفاده همزمان از تركيبات بروبيوتيكك و آنتى اكسيدانى مثل ALA، از طريق كاهش التهاب مىتواند در مديريت وزن و اشتها و همجنين لخههدارى وزن بعد از كاهش آن نقش مهمى داشته باشد. با فيا اين حال، مطالعات بيشترى براى ارائه شواهد اضافى مورد

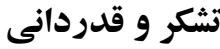

اين تحقيق حاصـل باياننامه كارشناسى ارشـد رشته تغذيه مربوط به غلامرضا نصيرى است كه در تاريخ نوا

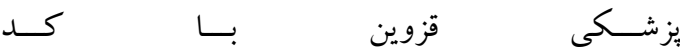
IR.QUMS.REC.1397.183 به تصــويب رسـيد. از معاونت محترم تحقيقات و فن آورى دانشكاه علوم يزشكى قزوين به عنوان حمايت كننده مالى تقدير و تشكر به عمل

$$
\text { مى آيد. }
$$

نتايج فاز دوم مطالعه حاضر، در مقايسه با نتايج مرحله اول، كاهش وزن رادر گروههاى مداخله نشان داد؛ اما اين تغيير فقط در گروهى كه به طور همزمان يروبيوتيك و ALA دريافت كرده بودند، معنىدار بود. همجِنين در اين مرحله، عوامل مختلف اشتها در گروههاى مداخله كاهش يافته بود ولى ميزان اين تغييرات تنها در گروه دريافت كننده همزمان يروبيوتيكك و ALA، معنىدار بود. در نتايج مطالعه Sanchez لاكتوباسيلوس، علاوه بر دوره كاهش وزن، در دوره نخهارى وزن نيز كاهش معنىدارى در ميزان وزن مشاهده كرديد، در حالى كه در گروه دارونما تغييرات معنىدار

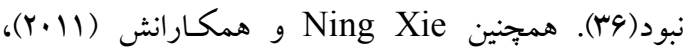

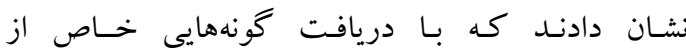
يروبيوتيـك هـا در رتهـا نظيـر لاكتوباسيلوس ترشح آميلاز و فعاليت ليياز در روده مهار و در نتيجه درصد جربى در بافت جربى كـاهش مى يابـد. در اين مطالعه مشخص

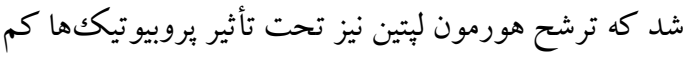
شد كه مىتواند دليلى بر كاهش اشتها باشد(YV).

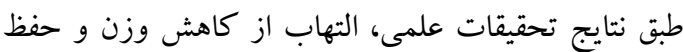

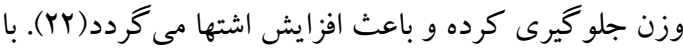
توجه به اثرات ضد التهابى يروبيوتيككها، مىتوان نتيجه كرفت كه بروبيوتيك ها با كاهش عوامل التهابى ماندا

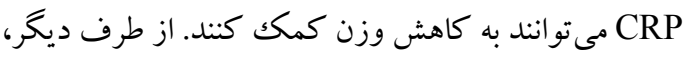
ALA به عنوان يكك آنتىاكسيدان قدرتمند، به تعادل باكترىهاى روده كمك كرده و از يروبيوتيك ها در برابر سموم دستگاه گوارش محافظت مى كند. 


\section{منابع}

1.Prentice AM. The emerging epidemic of obesity in developing countries. Int J Epidemiol. 2005;35(1):93-9

2.Afshin A, Forouzanfar MH, Reitsma MB, Sur P, Estep K, Lee A, et al. Health effects of overweight and obesity in 195 countries over 25 years. N Engl J Med. 2017;377(1):13-9

3.Hetherington M, Cunningham K, Dye L, Gibson E, Gregersen N, Halford J, et al. Potential benefits of satiety to the consumer: scientific considerations. Nutr Res Rev. 2013;26(1):22-8

4.Penn L, White M, Lindström J, den Boer AT, Blaak E, Eriksson JG, et al. Importance of weight loss maintenance and risk prediction in the prevention of type 2 diabetes: analysis of European Diabetes Prevention Study RCT. PLoS One. 2013;8(2):35-9

5.Mohammadi V, Khorvash F, Feizi A, Askari G. The effect of alpha-lipoic acid supplementation on anthropometric indices and food intake in patients who experienced stroke: A randomized, double-blind, placebo-controlled clinical trial. J Res Med Sci. 2017;22(98):17-22

6.Phung OJ, Baker WL, Matthews LJ, Lanosa M, Thorne A, Coleman CI. Effect of green tea catechins with or without caffeine on anthropometric measures: a systematic review and meta-analysis. AM J Clin Nutr. 2010;91(1):73-9

7.Hashemipour M, Kelishadi R, Shapouri J, Sarrafzadegan N, Amini M, Tavakoli N, et al. Effect of zinc supplementation on insulin resistance and components of the metabolic syndrome in prepubertal obese children. Hormones. 2009;8(4):280-6

8.Koh EH, Lee WJ, Lee SA, Kim EH, Cho EH, Jeong E, et al. Effects of alpha-lipoic acid on body weight in obese subjects. Am J Med. 2011;124(1):84-9

9.Thomas DW, Greer FR. Probiotics and prebiotics in pediatrics. Pediatrics. 2010;126(6):1217-31

10.Bäckhed F, Manchester JK, Semenkovich CF, Gordon JI. Mechanisms underlying the resistance to diet-induced obesity in germ-free mice. PNAS. 2007;104(3):979-84

11.Kadooka Y, Sato M, Imaizumi K, Ogawa A, Ikuyama K, Akai Y, et al. Regulation of abdominal adiposity by probiotics (Lactobacillus gasseri SBT2055) in adults with obese tendencies in a randomized controlled trial. Eur J Clin Nutr. 2010;64(6):636-40

12.Furukawa S, Fujita T, Shimabukuro M, Iwaki M, Yamada Y, Nakajima Y, et al. Increased oxidative stress in obesity and its impact on metabolic syndrome. $J$ Clin Invest. 2017;114(12):1752-61

13.Badran M, Abuyassin B, Golbidi S, Ayas N, Laher I. Alpha Lipoic Acid Improves Endothelial Function and Oxidative Stress in Mice Exposed to Chronic Intermittent Hypoxia. Oxid Med Cell Longev. 2019;22(19):25-9

14.Domingues CC, Kundu N, Kropotova Y, Ahmadi N, Sen S. Antioxidant-upregulated mesenchymal stem cells reduce inflammation and improve fatty liver disease in diet-induced obesity. Stem Cell Res Ther. 2019;10(1):280-6

15.Carbonelli M, Renzo L, Bigioni M, Daniele ND, De Lorenzo A, Fusco M. $\alpha$-Lipoic acid supplementation: a tool for obesity therapy?. Curr Pharm Des. 2010;16(7):840-6

16.Bernardin P, Moller A. Recommended daily caloric intake. FASEB J. 2013;27(11):19-25

17. Mason C, Katzmarzyk PT. Effect of the site of measurement of waist circumference on the prevalence of the metabolic syndrome. AM J Cardiol. 2009;103(12):1716-20

18.Marra M, Sammarco R, De Filippo E, Caldara A, Speranza E, Scalfi L, et al. Prediction of body composition in anorexia nervosa: Results from a retrospective study. Clin Nutr. 2017;10(9):12-9 
19.Mohammadi M, Akhondzadeh S, Keshavarz S, Mostafavi S-A. The Characteristics, Reliability and Validity of the Persian Version of Simplified Nutritional Appetite Questionnaire (SNAQ). J Nutr Health Aging. 2019;23(9):837-42

20.De Lorenzo A, Costacurta M, Merra G, Gualtieri P, Cioccoloni G, Marchetti M, et al. Can psychobiotics intake modulate psychological profile and body composition of women affected by normal weight obese syndrome and obesity? A double blind randomized clinical trial. J Transl Med. 2017;15(1):135-41

21.Hagan S, Niswender KD. Neuroendocrine regulation of food intake. Pediatr Blood Cancer. 2011;58(1):149-53

22.Field AE, Coakley EH, Must A, Spadano JL, Laird N, Dietz WH, et al. Impact of overweight on the risk of developing common chronic diseases during a 10-year period. Arch Intern Med. 2001;161(13):1581-6

23.Jung S-P, Lee K-M, Kang J-H, Yun S-I, Park H-O, Moon Y, et al. Effect of Lactobacillus gasseri BNR17 on overweight and obese adults: a randomized, double-blind clinical trial. Korean J Fam Med. 2013;34(2):80-7

24.Madjd A, Taylor MA, Mousavi N, Delavari A, Malekzadeh R, Macdonald IA, et al. Comparison of the effect of daily consumption of probiotic compared with low-fat conventional yogurt on weight loss in healthy obese women following an energy-restricted diet: a randomized controlled trial. Am J Clin Nutr. 2015;103(2):323-9

25.Augustine V, Gokce SK, Oka Y. Peripheral and central nutrient sensing underlying appetite regulation. Trends Neurosci. 2018;41(8):526-39

26.Holst JJ, Madsbad S, Bojsen-Møller KN, Svane MS, Jørgensen NB, Dirksen C, et al. Mechanisms in bariatric surgery: Gut hormones, diabetes resolution, and weight loss. Surg Obes Relat Dis. 2018;14(5):708-14

27.Lye H-S, Kuan C-Y, Ewe J-A, Fung W-Y, Liong M-T. The improvement of hypertension by probiotics: effects on cholesterol, diabetes, renin, and phytoestrogens. Int $\mathrm{J}$ Mol. 2009;10(9):3755-75

28.Gratz SW, Mykkanen H, El-Nezami HS. Probiotics and gut health: a special focus on liver diseases. World J Gastroenterol. 2010;16(4):403-8

29.Cani PD, Jordan BF. Gut microbiota-mediated inflammation in obesity: a link with gastrointestinal cancer. Nat Rev Gastroenterol Hepatol. 2018;15(11):671-82

30.Chambers ES, Viardot A, Psichas A, Morrison DJ, Murphy KG, Zac-Varghese SE, et al. Effects of targeted delivery of propionate to the human colon on appetite regulation, body weight maintenance and adiposity in overweight adults. Gut. 2015;64(11):1744-54

31.Kucukgoncu S, Zhou E, Lucas KB, Tek C. Alpha-lipoic acid (ALA) as a supplementation for weight loss: results from a meta-analysis of randomized controlled trials. Obes Rev. 2017;18(5):594-9

32.Namazi N, Larijani B, Azadbakht L. Alpha-lipoic acid supplement in obesity treatment: A systematic review and meta-analysis of clinical trials. Clin Nutr. 2018;37(2):419-28

33.Kim MS, Park JY, Namkoong C, Jang PG, Ryu JW, Song HS, et al. Anti-obesity effects of alpha-lipoic acid mediated by suppression of hypothalamic AMP-activated protein kinase. Nat Med. 2004;10(7):727-33.

34.Hu X, Wang Y, Sheikhahmadi A, Li X, Buyse J, Lin H, et al. Effects of dietary energy level on appetite and central adenosine monophosphate-activated protein kinase (AMPK) in broilers. Anim Sci J. 2019;97(11):4488-95 
35.Mohammadi V, Khalili M, Eghtesadi S, Dehghani S, Jazayeri S, Aghababaee SK, et al. The effect of alpha-lipoic acid (ALA) supplementation on cardiovascular risk factors in men with chronic spinal cord injury: a clinical trial. Spinal cord. 2015;53(8):621-4.

36. Sanchez M, Darimont C, Panahi S, Drapeau V, Marette A, Taylor V, et al. Effects of a diet-based weight-reducing program with probiotic supplementation on satiety efficiency, eating behaviour traits, and psychosocial behaviours in obese individuals. Nutrients. 2017;9(3):284-9

37.Xie N, Cui Y, Yin Y-N, Zhao X, Yang J-W, Wang Z-G, et al. Effects of two Lactobacillus strains on lipid metabolism and intestinal microflora in rats fed a high-cholesterol diet. BMC Complement Altern Med. 2011;11(1):53-8 